\title{
MACIÇOS GRANÍTICOS DE ESMOLFE E ANTAS - MATANÇA (PORTUGAL): RECONHECIMENTO, CARACTERIZAÇÃO E DEFINIÇÃO DE ÁREAS COM POTENCIALIDADE PARA EXPLORAÇÃO DE GRANITO ORNAMENTAL
}

\author{
ESMOLFE AND ANTAS - MATANÇA GRANITIC MASSIFS (PORTUGAL): \\ GENERAL GEOLOGICAL SURFACE STUDY, CHARACTERISATION AND \\ DEFINITION OF POTENTIAL AREAS FOR ORNAMENTAL GRANITE \\ QUARRYING
}

José Vítor Lisboa ${ }^{1}$

Daniel P. S. de Oliveira ${ }^{1}$

\begin{abstract}
RESUMO
O presente trabalho tem por objetivo o estudo de áreas com potencialidade para produção de pedra ornamental nos maciços graníticos de Esmolfe e Antas-Matança, na região Centro-Norte de Portugal. Os granitos estudados, tardi-hercínicos e de característica calco-alcalina, têm cor cinzenta azulada, granulação média e tendência levemente porfirítica. Apresentam acentuada homogeneidade mineralógica, textural e estrutural e escassos defeitos do ponto de vista ornamental, sendo a principal condicionante à atividade extrativa a fracturação. Procede-se à análise da informação colhida e tratamento estatístico dos dados de fracturação, visando ao conhecimento do estado de compartimentação dos maciços nos níveis superficiais, embora com as reservas inerentes à alietoriedade da rede de fracturação natural. No maciço de Esmolfe, a textura do granito é mais homogênea, apresentando uma granulação mais grosseira e cor mais clara do que o granito de Antas-Matança. Os espaçamentos dos sistemas de fracturas em ambos os maciços são maioritariamente moderados a amplos (1 a $6,25 \mathrm{~m}$ ). A atividade extrativa em Antas-Matança é ainda reduzida, enquanto em Esmolfe é intensa e sem planeamento. A proliferação exagerada de pedreiras, que raramente ultrapassam os níveis superficiais ( 2 a $3 \mathrm{~m}$ de profundidade), sem atingir níveis mais promissores, causa um elevado impacto visual. Foram definidas cinco áreas potenciais para exploração de granito ornamental em Antas-Matança e quatro em Esmolfe.
\end{abstract}

Palavras-chave: maciço, granito; pedra ornamental; fracturação; área potencial. 


\section{EXTENDED ABSTRACT}

The present investigation seeks to study the areas with dimension stone potential in the Antas-Matança and Esmolfe massifs, in central northern Portugal.

There are two massifs: the Esmolfe massif, with an outcrop area of $12 \mathrm{~km}^{2}$, is circular with a narrow offshoot to the NE and prolongs itself to the SE until the Antas-Matança massif. This latter massif is elliptic in shape, elongated in an E-W direction, with an outcrop area of approximately $19 \mathrm{~km}^{2}$.

Both granites studied are calc-alkaline, undeformed, blue-grey in colour, medium-grained with a slightly porphyritic tendency. They are regarded as part of the Celorico-Matança granite that has been dated at $252 \pm 9$ M.a. (Pinto et al. 1987).

The textural characteristics of the granite massifs are relatively homogeneous although variations do occur. The Antas-Matança facies shows some colour variations and heterogeneity in grain size. The Esmolfe facies is more homogeneous, coarser-grained, lighter in colour, due to aggregates of feldspar crystals, than the Antas-Matança facies. Superficial alteration of the Antas-Matança facies is greater than in the Esmolfe facies.

Due to the petrographic and textural characteristics of the granite under study, and small defects in terms of dimension stone production, the main limiting factor in defining favourable areas for dimension stone extraction is the fracture density pattern. Hence, this aspect is highlighted.

The paper proceeds to analyse field information and statistically treats fracture density data to understand and define the compartmentalisation of the massifs in the upper levels although limited to the inherent randomness of natural fracture patterns.

In the Esmolfe massif the main fracture orientation is $\mathrm{N} 15-30^{\circ} \mathrm{W}$ (total population) in 16 of the 22 lines considered both as main or secondary fracture sets (Table 1 ). In this system $50 \%$ of the fracture spacing are $<1 \mathrm{~m}$ although there is considerable dispersion.

The spacing between main fracture sets varies considerably in most cases with no regularity in spacing patterns.

The total population in the Antas-Matança massif shows there to be two main orientation directions 40$50^{\circ}$ and $150-160^{\circ}$ that are sub vertical in nature. In both sets spacing is $<1 \mathrm{~m}(65 \%$ of total). This implies that the set $40-50^{\circ}$ penalises a few of the areas due to high frequencies of closely spaced fractures $(<0.3 \mathrm{~m})$.

Fracture spacing in both massifs are considered moderate $(1-2.5 \mathrm{~m})$ to ample $(2.5-6.25 \mathrm{~m})$. Comparison of the class frequencies of distance between consecutive fractures shows that the distribution of intervals is similar in both the Esmolfe and Antas-Matança massifs where, in the latter, reduced spacing predominates. However, if we compare the average distance frequencies between fractures in the scan-lines, the spacing between fractures in Esmolfe appears to be greater than in Antas-Matança (Fig. 9B). This is mainly due to the high frequency of reduced spacing in the Antas-Matança massif that lowers the average distance between fractures. In Esmolfe, one third of the lines studied, the average spacing is $<2 \mathrm{~m}$. These factors, in conjunction with the textural homogeneity of the rock, mineralogical characteristics and other factors, such as favourable topographic conditions, easy access and large reserves demonstrate the high ornamental potential of these granites.

The quarrying activity in Esmolfe is intense and chaotic. The exaggerated proliferation of quarries that hardly ever go beyond the superficial levels causes a high negative visual impact. The lack of technical management in the majority of quarries implies that rarely the more promising levels are ever extracted resulting in the premature closure of the quarry.

The Esmolfe granite is commercialised under various designations of which Cinza (grey) is the most common. It outcrops generally in large boulders that due to their dimension alone allow the installation of the quarries. Alteration profile is generally $<0.2 \mathrm{~m}$.

The extraction activity of the Antas-Matança massif is presently restricted to three quarries, being the granite commercialised under the designation Cinza (grey) or Cinzento Antas (Antas grey). The existence of extensive slabs of this facies with a reduced alteration profile creates very favourable conditions for dimension stone extraction.

This study shows that the Esmolfe massif has potential for extraction in four areas located SW of Pedras Altas and S of Ponte do Ferreira (Map 1). For the Antas-Matança massif 5 areas are proposed, namely the outcrops nearby Pisão, Lameira area (station A24), Antas and Abrocedo areas (Map 2).

The importance of this study is clearly shown not only for territorial land planning uses, in the selection and hierarchisation, of potential areas but also to better plan exploration methodologies (e.g. use of georadar or percussion drilling), if the raw material warrants it.

Key-words: maciço, granito; pedra ornamental; fracturação; área potencial. 


\section{INTRODUÇÃO}

Os maciços graníticos de Esmolfe e de AntasMatança situam-se na região Centro-Norte de Portugal, entre as cidades de Viseu e Guarda (figura 1A).

Ocupam uma área total de cerca de $31 \mathrm{~km}^{2}$. O maciço granítico de Esmolfe aflora numa área de aproximadamente $12 \mathrm{~km}^{2}$, e situa-se imediatamente a NE da vila com o mesmo nome. Com forma subcircular, apresenta uma estreita faixa a NE, por vezes com menos de $0,5 \mathrm{~km}$ de largura, prolongando-se para SE até o maciço granítico de Antas-Matança, o qual exibe uma forma elíptica alongada. Este, cobrindo uma área de cerca de $19 \mathrm{~km}^{2}$, tem $10 \mathrm{~km}$ de comprimento segundo o eixo maior, orientado E-W, e largura máxima de 2,5 a $3 \mathrm{~km}$ (figura 1).

Embora os granitos que constituem os dois maciços - granito de Esmolfe e granito de Antas-Matança apresentem características texturais distintas, do ponto de vista genético, quanto à idade e composição mineralógica são semelhantes, sendo englobados na cartografia atualmente existente, numa mesma faciologia, o granito de Celorico-Matança (GONÇALVES et al., 1990). Assim, quando no texto nos referimos ao granito de Celorico-Matança, reportamo-nos à idade e constituição mineralógica da rocha. Quando importa descrever aspectos particulares da rocha num maciço em particular, referimo-nos ao granito de Esmolfe ou ao granito de AntasMatança.

O presente trabalho tem como objectivo o estudo de áreas com potencialidades para produção de pedra ornamental, em ambos os maciços, visto o granito que os constitui apresentar características ornamentais.

\section{ENQUADRAMENTO GEOLÓGICO}

Os maciços de Esmolfe e Antas-Matança enquadram-se num extenso maciço de granitos calco-alcalinos, não deformados, orientados segundo NW-SE, que se estende por mais de $200 \mathrm{~km}$.

Paleogeograficamente estes granitos inserem-se na Zona Centro-Ibérica (LOTZE; RIBEIRO, 1979) e situam-se numa faixa ao longo do rio Mondego, limitada por fracturas tardi-hercínicas de orientação NNE-SSW.

O granito de Celorico-Matança, pós-tectónico relativamente à fase $\mathrm{F}_{3}\left(3^{\circ}\right.$ evento tectónico hercínico com compressão máxima NE-SW), foi datado de $252 \pm 9$ M.a., pelo método de Rb-Sr, rocha total (PINTO et al., 1987). Faz contacto na área estudada, com granitos tardi a póstectónicos, acentuadamente porfiríticos e mais ricos em biotita (GONÇALVES et al., 1990), podendo ser observados na figura 1B. Estes granitos têm geralmente granulação grosseira, excepto na zona sul dos corpos, onde apresentam granulação média.
Recortando a mancha granítica de Esmolfe, ocorre um tipo moscovítico, de granulação fina e com estrutura filoneana, de orientação NE-SW.

No maciço de Antas-Matança, junto à localidade de Forcado, ocorre uma faixa de granito de granulação fina, pré-tectónico (granito de Almeidinha-Fuinhas-Cortiçô). Os maciços em apreço estão ligados junto ao rio Dão, pelo granito de Vila Cova do Covelo, de carácter sintectónico relativamente à fase $\mathrm{F}_{3}$.

As rochas metassedimentares anteriores à atividade ígnea, em contacto com a fácies Celorico-Matança, restringem-se a três pequenos afloramentos câmbricos, situados nos bordos $\mathrm{E}, \mathrm{W}$ e $\mathrm{S}$ do maciço de Antas-Matança. O bordo $\mathrm{N}$ deste maciço faz contato em grande parte com quartzitos finos, xistos metapelíticos e grauvaques metamorfizados, de idade ordovícica.

O relevo é condicionado pela existência de linhas de água de orientação NE-SW, concordantes com a orientação das fracturas. Este aspecto é mais evidente no maciço de Esmolfe (figura 13).

Os contatos com os granitos mais antigos (ante a tardi a pós-tectónicos), na mancha de Antas-Matança, são relativamente bem marcados. Estes contactos também se traduzem no plano topográfico, em zonas relativamente aplanadas nos granitos de granulação mais fina, contrastantes com os relevos mais acentuados, em granitos de grão grosso.

\section{DESCRIÇÃO DOS GRANITOS}

Os granitos de Esmolfe e Antas-Matança são geneticamente equivalentes ao Granito de Celorico da Beira, de granulação média, com duas micas e tendência porfirítica, caracterizando-se, geoquimicamente, como rochas peraluminosas. A compartimentação do corpo intrusivo e as características das juntas tornam mais freqüente $o$ afloramento de lajes em Antas-Matança e penedos (matacões) de grande dimensão, na área de Esmolfe.

\section{CARACTERÍSTICAS PETROGRÁFICAS}

O granito de Esmolfe (figura 2A) é composto por quartzo, feldspato (microclina e plagioclase), biotite \pm clorite, moscovite, sericite, rútilo e zircão. Como fase acessória de óxidos, contém ilmenite disseminada ao longo das superfícies de clivagem da biotite.

O quartzo é tipicamente anédrico, com extinção ondulante localizada, que coexiste com grãos sem extinção ondulante.

Os feldspatos podem apresentarem-se ligeiramente alterados. Esta alteração é evidenciada por bordos corroídos e alteração sericítica no núcleo. Neste granito, 

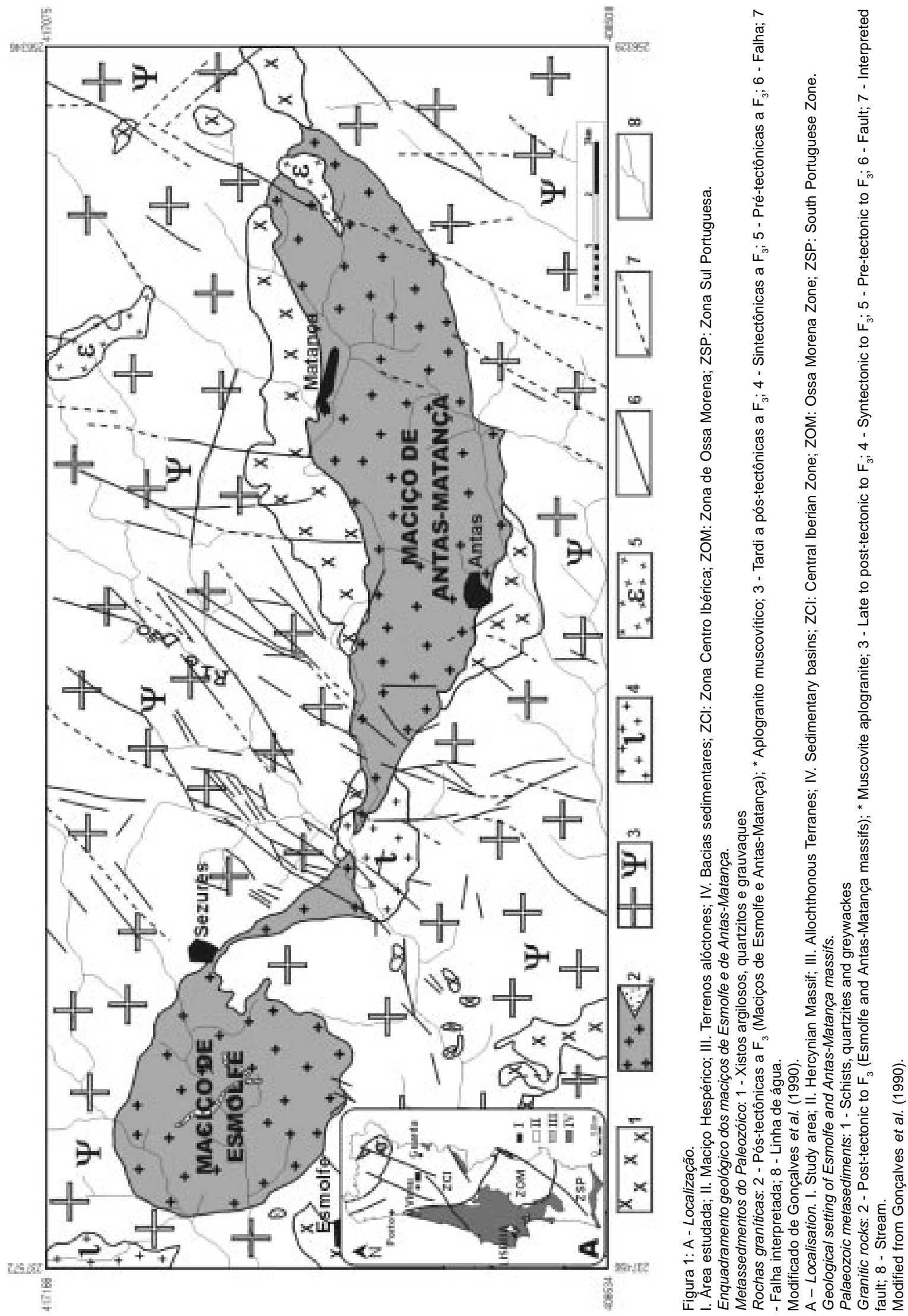

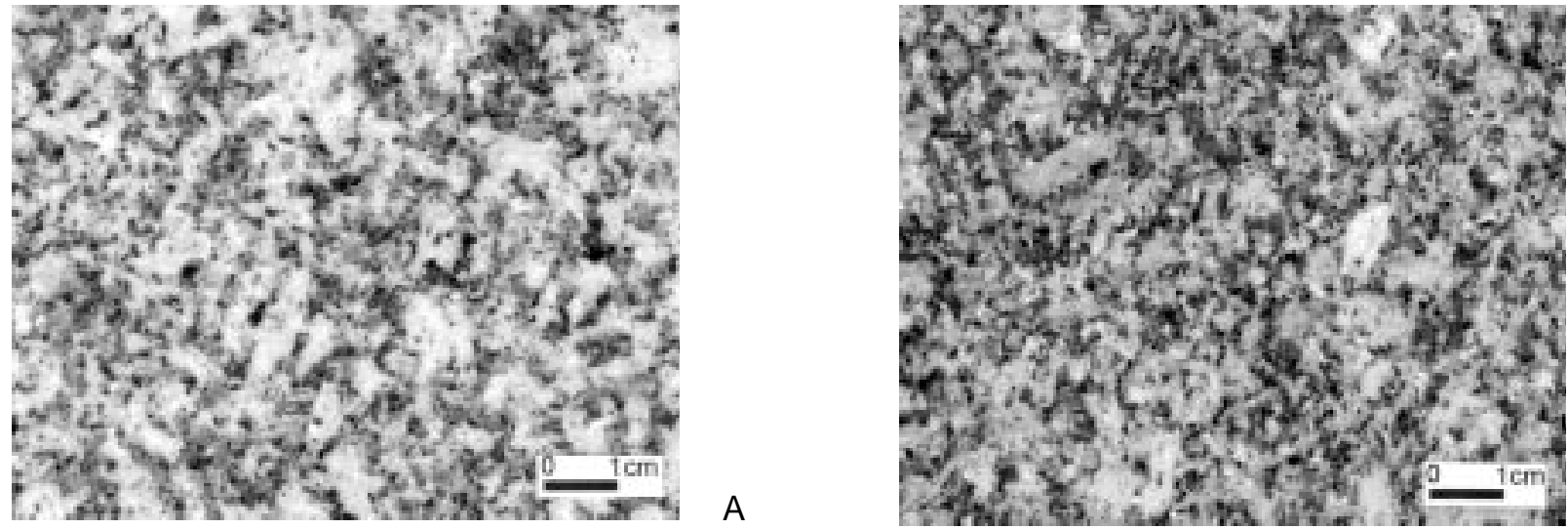

Figura 2: Texturas típicas das regiões de Esmolfe e de Antas-Matança (amostras em chapa polida). A) granito de Esmolfe na pedreira Albugranitos. B) granito de Antas-Matança na pedreira da Incoveca. Typical granitic textures observed in the Esmolfe e Antas-Matança area (polished slab samples). A) Esmolfe granite in the Albugranitos quarry. B) Antas-Matança granite in the Incoveca quarry.

predominam feldspatos não alterados. Algumas zonas com textura mirmequítica foram também observadas. Os feldspatos, de cor branca leitosa, podem atingir $15 \mathrm{~mm}$ de comprimento. As micas observadas (biotite, moscovite e sericite) são subédricas a anédricas. A biotite pode apresentar fina alteração nos bordos (2-3um). Foi observada em algumas laminas delgadas, alteração incipiente da biotite para clorite. $O$ tamanho dos grãos varia entre $30 \mu \mathrm{m}$ e 1,4 mm, nas amostras estudadas. A moscovite, menos abundante do que a biotite, mostra cristais ( $>700$ $\mu \mathrm{m}$ de largura), que são cortados por veios finos de quartzo, que mantêm ainda a sua continuidade óptica. Os bordos da moscovite, tal como os dos feldspatos, são corroídos.

A sericite, pouco freqüente, apresenta cristais com dimensão superior a $1 \mathrm{~mm}$, e ocorre intersticialmente em relação ao quartzo e feldspato.

O granito de Antas-Matança (figura 2B) apresenta essencialmente a mesma mineralogia do granito de Esmolfe, embora tenham sido observados três grãos de cassiterite, além da ilmenite.

Microscopicamente, o granito de Antas-Matança apresenta textura hipidiomórfica granular, sendo composto por microclina (42\%) pertítica e poicilítica, quartzo (31\%) e plagioclase (18\%). Os minerais acessórios são biotite e moscovite (total de 8\%), zircão e rútilo, sericite e clorite como minerais de alteração (MOURA et al., 1996; RAMOs et al., 1997). Em lâmina delgada, este granito apresenta cristais de feldspato menores do que o granito de Esmolfe (podem atingir $6 \mathrm{~mm}$ de comprimento). Estes estão intensamente alterados para sericite no seu núcleo. A sericite ocorre de duas formas: como produto de alteração dos feldspatos e como produto de alteração da biotite.

\section{FRACTURAÇÃO}

A relativa homogeneidade das fácies graníticas estudadas, em termos petrográficos e texturais, implica que a fracturação seja o principal fator condicionante da sua aptidão ornamental, razão pela qual lhe é dada maior importância neste trabalho.

O reconhecimento inicial do estado de fracturação dos maciços estudados foi efectuado com o auxílio de fotografias aéreas na escala 1:15.000, visando à identificação do padrão de fracturação regional e a delimitação dos domínios menos fracturados. Reconheceram-se outros aspectos que influenciaram na selecção dos alvos potenciais: situações de topografia mais adequada, vias de acesso e proximidades de povoados.

Os fotolineamentos detectados compreendem fracturas, falhas ou zonas de falha e filões.

As direções regionais de fractura em Esmolfe, embora variáveis, apresentam as seguintes orientações preferenciais: NE, N-S e NW.

No domínio de Antas-Matança, existe a predominância de orientação de fracturas NE a NNE, NNW, E-W e N-S.

\section{Estudo dos Sistemas de Fracturas}

O estudo do padrão de fracturação na escala de afloramento, ou seja, a orientação e densidade dos sistemas principais de juntas, foi efetuado com base na amostragem sistemática de fracturas, selecionando-se os locais considerados mais adequados. Esta amostragem foi feita com base no estabelecimento de linhas de observação (scan-lines), orientadas preferencialmente perpendiculares ao principal sistema de juntas. 
Sempre que os afloramentos o justificavam e permitiam, realizaram-se pelo menos duas scan-lines perpendiculares entre si.

O espaçamento entre fracturas é um dos parâmetros mais importantes para avaliar a aptidão ornamental da rocha num maciço, indispensável para o cálculo da célula unitária (blocometria). No entanto, a sua estimativa nem sempre é direta, devido ao freqüente condicionamento da direção segundo a qual é efetuada a amostragem, não sendo sempre possível escolher as direções perpendiculares aos principais sistemas de juntas. Assim, nestes casos, foram obtidas distâncias e não espaçamentos.

O efeito da orientação das scan-lines, na estimativa do espaçamento entre juntas subparalelas consecutivas $(L)$, foi corrigido com base numa relação trigonométrica (LAPOINTE; HUDSON, 1985), onde: $L=$ a cos q, em que q é o ângulo entre a scan-line e a perpendicular às juntas consecutivas, e a é o comprimento medido.

Este efeito pode, assim, ser corrigido, mas a dispersão de orientações das juntas ao longo de uma mesma linha não permite o cálculo de todos os espaçamentos numa scan-line.

O espaçamento médio entre juntas, embora facilmente quantificável, tem um significado relativo, devido a fatores como a assimetria das distribuições ou a ocorrência de juntas subparalelas, agrupadas (clusters), as quais, quando muito próximas, falseiam o valor médio real. Para reduzir a perturbação induzida por estes fatores no cálculo do espaçamento médio, recorreu-se a outros parâmetros.

A análise dos espaçamentos dos principais sistemas de juntas em cada estação (local de medição e registo de dados) (quadros 1 e 3; figura 13 e 14) consistiu na verificação de valores máximos e mínimos e cálculo da média aritmética e mediana, esta última mais robusta do que a média e menos sensível aos dados outliers de cada distribuição.

Para avaliar a dispersão dos espaçamentos, calculou-se o desvio-padrão e, para comparar as dispersões em diferentes linhas de observação, optou-se por utilizar a dispersão relativa ou coeficiente de variação $(C V=100 * \mathrm{~S} /$ $\mathrm{m}$ ), que expressa o desvio-padrão como percentagem do valor médio.

A densidade de fracturação foi estimada pela freqüência de diaclasamento (número de juntas por unidade de comprimento). Esta, por si só, não permite uma avaliação do potencial ornamental da rocha, pois um valor elevado não implica em uma fraca qualidade ornamental. A situação existe quando ocorrem sistemas de juntas muito próximas $(<0,5 \mathrm{~m})$, alternadas com espaçamentos maiores.
Calculou-se ainda o produto das médias dos espaçamentos em scan-lines ortogonais entre si, sempre que existiam unicamente dois sistemas subverticais, de modo a obter a área média entre fracturas.

Verifica-se nos afloramentos uma heterogeneidade bastante elevada nos espaçamentos entre juntas, com valores máximos de $17 \mathrm{~m}$.

O diaclasamento suborizontal é geralmente irregular, com espaçamento muito variável, que tende a diminuir rapidamente com a profundidade.

A persistência das juntas nos sistemas principais é em geral elevada (10-20 m).

De acordo com a classificação ISRM-CSLF (1978), a abertura das juntas varia de cerrada $(0,1-0,25 \mathrm{~mm})$ a cerca de $30 \mathrm{~cm}$, valor no intervalo de classe extremamente aberta (10 -100 cm). com a maioria delas apresentando aberturas inferiores a $1 \mathrm{~mm}$, ou seja, entre cerradas e moderadamente abertas $(2,5-10 \mathrm{~mm})$.

A observação conjunta dos parâmetros obtidos fornece indicações qualitativas e quantitativas sobre 0 estado de compartimentação da rocha num local ou em uma pequena área envolvente. Deste modo, é possível inferir as características da fracturação e avaliar os locais estudados em termos de aptidão ornamental.

\section{Deslocamentos nas juntas}

A direção e magnitude de eventuais deslocamentos superficiais nas juntas fornecem informação sobre a sua origem e deformação a que foram sujeitas. Para detectar pequenas deslocações em juntas fechadas ou com abertura muito reduzida, correlacionou-se, sempre que possível, marcadores (cristais) do granito em lados opostos do traço da junta. Os filões e inclusões máficas também servem como marcadores passivos que registram o movimento ao longo das juntas (SEGALL; POLLARD, 1983).

A avaliação das juntas, em ambos os maciços, não revelou deslocamentos discerníveis macroscopicamente. Esta observação indica que o deslocamento tangencial relativo, se ocorreu, foi menor do que a dimensão do grão. As observações de campo evidenciam que, a maioria das juntas estudadas não é qualificada como sendo resultante de cizalhamento. Na área estudada, as juntas formaram-se inicialmente como fracturas de distensão (dilational fractures).

\section{RESULTADOS OBTIDOS}

A análise da compartimentação dos dois maciços graníticos, juntamente com as características de alteração da rocha, e à escala dos afloramentos, permitiu fa- 
zer uma seleção das áreas, que apresentam maior potencialidade para instalação de pedreiras, com vista à exploração de granitos como pedra ornamental.

As figuras 13 e 14 mostram a localização das estações onde foram colhidos os dados estruturais e as rosetas vectoriais com a freqüência das superfícies de fractura.

\section{MACIÇO DE ESMOLFE}

No maciço de Esmolfe, as juntas mais freqüentes (figura 3) têm orientação azimutal geográfica $150-165^{\circ}$; os mergulhos são elevados, maioritariamente subverticais, embora se verifique uma tendência para o quadrante NE. Identificam-se, com menor freqüência, descontinuidades com orientação $15-30^{\circ}$ e entre $90-150^{\circ}$ com esta última exibindo uma dispersão elevada. As inclinações destas fracturas são superiores a $60^{\circ}$, com predomínio de subverticais.

A importância da orientação de fractura 150 -165는 no nível da população total, confirma-se pela ocorrência de sistemas com esta direção, entre 16 das 22 linhas consideradas, seja como sistemas principais ou secundários (quadro 1).

Neste sistema, apesar da dispersão acentuada, $50 \%$ dos espaçamentos observados são inferiores a $1 \mathrm{~m}$ (figura 4A). Os intervalos de espaçamento propostos estão de acordo com a classificação para rochas graníticas (figura 4B) apresentada por García (1995); para identificar agrupamentos de fracturas muito próximas, modificou-se o intervalo definido como espaçamento reduzido

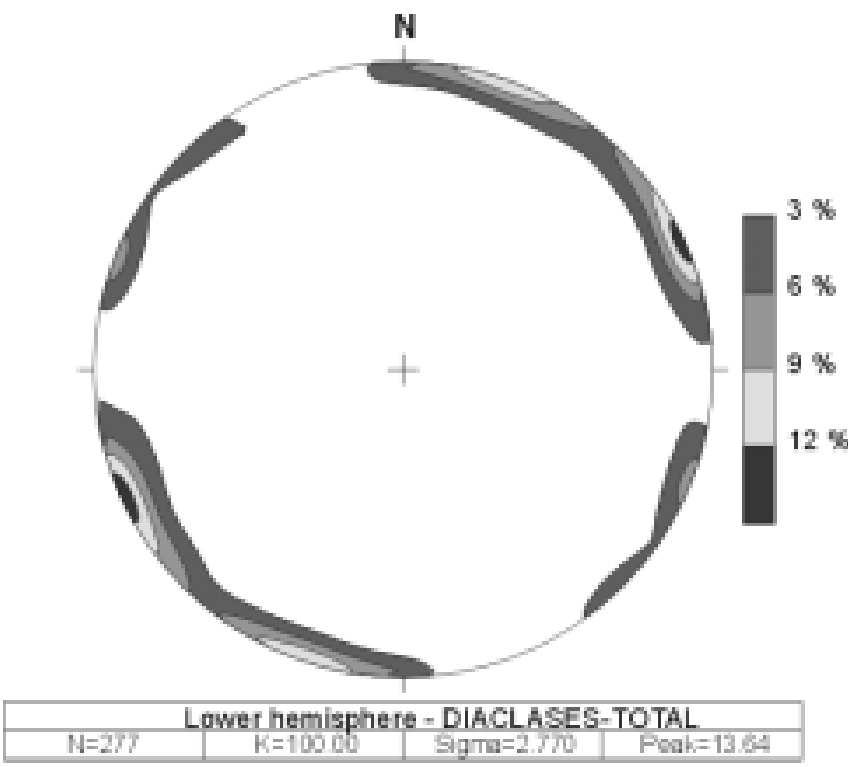

Figura 3: Estereograma dos dados obtidos em todas as estações de Esmolfe. Diagrama de contornos de densidade (rede de Schmidt - Lambert). Contornos a 3-6-9-12\%. Distribution of fracturing data in the Esmolfe massif. Density contour diagram for the poles of all the measured fracture planes (Schmidt Lambert net). Contours at 3-6-9-12\% intervals.
$(<1 \mathrm{~m})$, no qual passam a ser considerados espaçamentos inferiores a 0,3m e compreendidos entre 0,3 e $1 \mathrm{~m}$.

Os espaçamentos entre juntas dos principais sistemas têm, em sua maioria, variação elevada, havendo, portanto, irregularidade no espaçamento (quadro 1).

As juntas sistemáticas, ou seja, aquelas que se agrupam em famílias (geralmente planares e com orientação constante) são as que têm geralmente maior influência no tamanho do bloco natural. Em Esmolfe, as juntas não sistemáticas (tendência irregular e com formas curvas ou concoidais) nos níveis superficiais têm maior importância do que em Antas-Matança. Por isto, o padrão de afloramento consiste em formas predominantemente arredondadas, em que evidencia-se uma tendência freqüente, da rocha se fracturar em superfícies curvas.

Os dados relativos às distâncias entre fracturas no maciço de Esmolfe são apresentados no quadro 2. Aqui também se mantém a tendência irregular, ao longo das scan-lines.

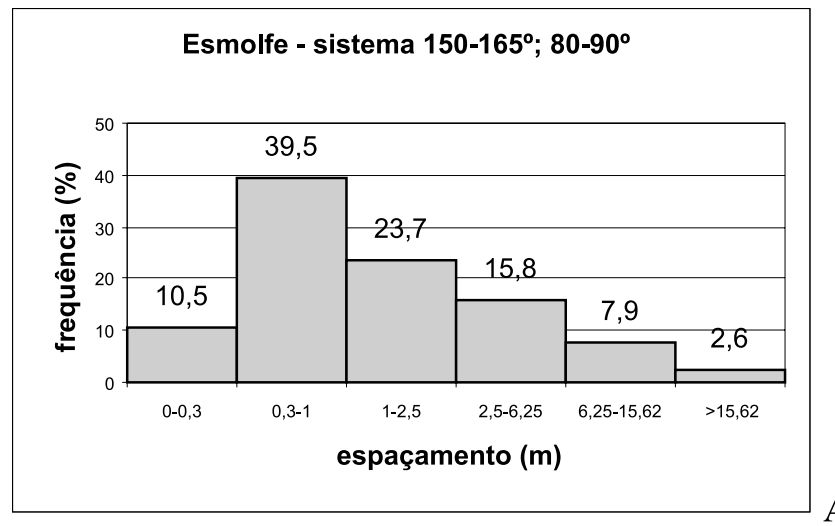

Tipos de espaçamento de juntas

Intervalo (m)

Espaçamento

0 - 1

Reduzido

$1-2.5$

Moderado

$2.5-6.25$

Amplo

$6.25-15.62$

Muito amplo

$>15.62$

Extremamente amplo B

Figura 4: A) Histograma de freqüência dos espaçamentos entre juntas, observados no sistema principal à superfície, no maciço de Esmolfe; os intervalos de classe foram modificados a partir da classificação anexa. B) Tipos de espaçamento de juntas segundo intervalos (rochas graníticas) definidos a partir dos tamanhos comerciais mínimos para blocos extraídos de qualidade standard (GARCÍA et al. 1995). A) Frequency histogram of the spacing between joints, in the main joint system observed in the Esmolfe massif; class intervals modified from the classification in B. B) Joint spacing types (granitic rocks) with defined intervals based on the minimum commercial size for standard quality blocks (GARCIA et al. 1995). 
LISBOA, J. V.; OLIVEIRA, D. P. S. Maciços graníticos de Esmolfe e Antas - Matança...

Quadro 1: Sistemas de fracturas observados no maciço de Esmolfe, nas estações onde se obtiveram dados de fracturação. Espaçamento entre fracturas em cada sistema: $\left(\mathbf{m}_{\mathrm{a}}\right)$ média aritmética, mediana, valor mínimo e máximo observados. $(\mathbf{N})$ número de medidas inventariadas. Nas estações onde houve impossibilidade de verificar os espaçamentos, foram registradas apenas as atitudes das fracturas. * Valores de espaçamento corrigidos. Table 1. Joint systems in the Esmolfe geological stations where fracturing data was collected. Spacing between joints in each system: ( $\boldsymbol{m}_{\mathrm{a}}$ ) arithmetic average, median, minimum and maximum observed value. (N) Number of data. In the stations where spacing could not be observed, only joint attitude was registered. * Corrected spacing values.

\begin{tabular}{|c|c|c|c|c|c|c|c|c|}
\hline \multirow[t]{2}{*}{ Estação } & \multirow{2}{*}{$\begin{array}{l}\text { Sistemas } \\
\text { principais }\end{array}$} & \multicolumn{5}{|c|}{ Espaçamento (m) } & \multicolumn{2}{|c|}{ Sistemas secundários } \\
\hline & & $\mu_{\mathrm{a}}$ & Mediana & mínimo & máximo & $\mathbf{N}$ & & \\
\hline E1 & $125-140 ; 90\left(^{*}\right)$ & 2.02 & 1.10 & 0.17 & 8.05 & 14 & $155-170 ; 85$ & \\
\hline E2 & $20-30 ; 90$ & 1.33 & 0.90 & 0.30 & 5.05 & 13 & $80-90 ; 85$ & \\
\hline E3 & $355-10 ; 70-80$ & 5.01 & 5.90 & 1.00 & 8.85 & 7 & $140-150 ; 90$ & $140-155 ; 80-90$ \\
\hline E4 & $330-345 ; 70-85$ & 0.75 & 0.90 & 0.10 & 1.70 & 14 & $350-0 ; 80-90$ & \\
\hline E5 & $100-120 ; 90$ & $\begin{array}{c}3.53 \\
-\end{array}$ & $\begin{array}{c}3.15 \\
-\end{array}$ & $\begin{array}{c}1.00 \\
-\end{array}$ & $\begin{array}{c}6.80 \\
-\end{array}$ & 6 & $\begin{array}{c}150-160 ; 90 \\
40-50 ; 90\end{array}$ & $120-130 ; 90$ \\
\hline E6 & $155-160 ; 80-90$ & 4.65 & 1.05 & 0.50 & 16.00 & 6 & $40 ; 90$ & \\
\hline E7 & $\begin{array}{l}345-0 ; 60-80 \\
160-170 ; 90\end{array}$ & $\begin{array}{c}1.57 \\
-\end{array}$ & $\begin{array}{c}1.10 \\
-\end{array}$ & $\begin{array}{l}0.65 \\
0.35\end{array}$ & $\begin{array}{l}2.90 \\
0.10\end{array}$ & $\begin{array}{l}7 \\
2\end{array}$ & $300 ; 80$ & \\
\hline E8 & $60 ; 70-80$ & 0.59 & 0.53 & 0.2 & 1.4 & 10 & $180-195 ; 80$ & \\
\hline E10 & $\begin{array}{l}310-330 ; 65-80 \\
285-300 ; 80-90\left(^{*}\right)\end{array}$ & $\begin{array}{l}0.47 \\
1.44\end{array}$ & $\begin{array}{l}0.15 \\
0.75\end{array}$ & $\begin{array}{l}0.09 \\
0.47\end{array}$ & $\begin{array}{l}1.64 \\
5.92\end{array}$ & $\begin{array}{l}8 \\
9\end{array}$ & $220-235 ; 55-65$ & $110-120 ; 80-90$ \\
\hline E11 & $45-55 ; 85-90$ & 2.68 & 1.58 & 0.45 & 6.05 & 10 & $160-165 ; 90$ & \\
\hline E11A & $\begin{array}{l}100-110 ; 90 \\
150-160 ; 90\end{array}$ & $\begin{array}{l}2.20 \\
2.50\end{array}$ & $\begin{array}{l}2.40 \\
2.38\end{array}$ & $\begin{array}{l}1.80 \\
0.85\end{array}$ & $\begin{array}{l}2.40 \\
3.85\end{array}$ & $\begin{array}{l}5 \\
7\end{array}$ & $120-125 ; 90$ & $105-120 ; 90$ \\
\hline E12 & $110-120 ; 90$ & 1.43 & 1.10 & 0.45 & 2.75 & 15 & $145-160 ; 90$ & \\
\hline E13 & $\begin{array}{l}15-25 ; 90 \\
140-155 ; 90\left(^{*}\right)\end{array}$ & $\begin{array}{l}1.36 \\
1.10 \\
\end{array}$ & $\begin{array}{l}0.93 \\
1.13 \\
\end{array}$ & $\begin{array}{l}0.25 \\
0.06 \\
\end{array}$ & $\begin{array}{c}8.7 \\
2.20 \\
\end{array}$ & $\begin{array}{l}10 \\
12 \\
\end{array}$ & & \\
\hline E14 & $90-110 ; 90$ & 0.93 & 0.50 & 0.2 & 3.1 & 18 & $160 ; 90$ & \\
\hline E15 & $320 ; 80-90$ & 2.51 & 1.00 & 0.25 & 8.7 & 9 & $5 ; 80$ & \\
\hline E16 & $90-105 ; 90$ & 3.80 & 2.25 & 0.45 & 12.6 & 7 & $155 ; 90$ & \\
\hline E17 & $145-155 ; 85-90$ & 1.2 & 0.70 & 0.5 & 2.8 & 8 & & \\
\hline
\end{tabular}

Quadro 2: Distribuição estatística das observações nas scan-lines do maciço de Esmolfe. $(\mathrm{m})$ média aritmética, (DP) desvio padrão da média aritmética, (CV) coeficiente de variação, mediana, (N) número de intersecções, (L) comprimento da scan-line, (fF) freqüência da fracturação. * Valores de espaçamento corrigidos. Table 2. Statistical distribution of scan lines data in Esmolfe. $\left(\boldsymbol{m}_{\mathrm{a}}\right)$ arithmetic average, (DP) standard deviation, $(\mathrm{CV})$ variation coefficient, median, $(\mathrm{N})$ intersection number, $(L)$ scan line width, (fF) fracturing frequency. * Corrected spacing values.

\begin{tabular}{|l|l|l|l|l|l|l|l|l|l|c|}
\hline Estação & Azimute & \multicolumn{1}{|c|}{$\mu_{\mathbf{a}}$} & \multicolumn{1}{|c|}{$\mathbf{D P}$} & $\mathbf{C V}$ & Mediana & Mínimo & Máximo & $\mathbf{N}$ & $\mathbf{L}$ & $\mathbf{f F}$ \\
\hline E1 & $20^{*}$ & 1.71 & 1.5 & 0.88 & 1.09 & 0.17 & 5.52 & 20 & 34.1 & 0.59 \\
\hline & 110 & 2.43 & 1.47 & 0.60 & 2.78 & 0.5 & 3.65 & 4 & 9.7 & 0.41 \\
\hline E2 & 170 & 2.55 & 2.84 & 1.11 & 1.25 & 0.1 & 6.6 & 6 & 15.3 & 0.39 \\
\hline & $110^{*}$ & 1.21 & 1.21 & 1.00 & 0.98 & 0.2 & 5.6 & 20 & 24.2 & 0.83 \\
\hline E3 & 90 & 3.09 & 2.4 & 0.78 & 2.90 & 0.75 & 6.45 & 7 & 21.6 & 0.32 \\
\hline & $160^{*}$ & & & & & 2.65 & 8.85 & 2 & 11.5 & 0.17 \\
\hline E4 & 50 & 0.75 & 0.51 & 0.68 & 0.90 & 0.1 & 1.7 & 12 & 9 & 1.33 \\
\hline & 60 & 2.23 & 1.64 & 0.74 & 2.00 & 0.25 & 4.15 & 11 & 24.55 & 0.45 \\
\hline E5 & $25^{*}$ & 4.05 & 3.2 & 0.79 & 3.34 & 1 & 8.54 & 6 & 24.3 & 0.25 \\
\hline & 120 & 3 & 2.16 & 0.72 & 2.35 & 1.2 & 6.1 & 4 & 12 & 0.33 \\
\hline
\end{tabular}




\begin{tabular}{|l|l|l|l|l|l|l|l|l|l|l|}
\hline E6 & 65 & 4.8 & 6.53 & 1.36 & 1.05 & 0.5 & 16 & 6 & 28.8 & 0.21 \\
\hline E7 & $100^{*}$ & 2.64 & 4.63 & 1.75 & 0.85 & 0.1 & 13.9 & 9 & 21.1 & 0.43 \\
\hline & $20^{*}$ & 6.38 & 10.45 & 1.64 & 0.65 & 0.05 & 18.45 & 3 & 19.15 & 0.16 \\
\hline E8 & $150^{*}$ & 0.78 & 1.06 & 1.36 & 0.34 & 0.02 & 3.75 & 16 & 12.46 & 1.28 \\
\hline & $60^{*}$ & 1.54 & 1.27 & 0.82 & 1.14 & 0.59 & 3.85 & 9 & 13.89 & 0.65 \\
\hline E10 & $60^{*}$ & 0.99 & 1.55 & 1.57 & 0.50 & 0.15 & 6.3 & 13 & 13.5 & 0.96 \\
\hline & $90^{*}$ & 1.7 & 2.01 & 1.18 & 0.65 & 0.05 & 5.05 & 8 & 13.4 & 0.60 \\
\hline E11 & 140 & 2.14 & 2.01 & 0.94 & 1.10 & 0.15 & 6.05 & 10 & 21.4 & 0.47 \\
\hline & $55^{*}$ & 1.78 & 1.11 & 0.62 & 1.50 & 0.42 & 3.19 & 10 & 17.81 & 0.56 \\
\hline E11a & 60 & 1.77 & 1.61 & 0.91 & 1.33 & 0.05 & 3.85 & 6 & 10.6 & 0.57 \\
\hline & $10^{*}$ & 1.52 & 0.83 & 0.55 & 1.60 & 0.4 & 2.45 & 7 & 11.5 & 0.61 \\
\hline E12 & 20 & 1.17 & 0.67 & 0.57 & 1.00 & 0.45 & 2.3 & 10 & 11.65 & 0.86 \\
\hline E12a & $20^{*}$ & 2.47 & 1.9 & 0.77 & 2.75 & 0.65 & 5.82 & 8 & 17.26 & 0.46 \\
\hline E13 & $125^{*}$ & 1.58 & 1.54 & 0.98 & 0.90 & 0.25 & 5.65 & 19 & 30 & 0.63 \\
\hline & 40 & 1.88 & 1.11 & 0.59 & 1.71 & 0.47 & 3.48 & 6 & 11.28 & 0.53 \\
\hline E14 & 22 & 0.95 & 0.77 & 0.81 & 0.68 & 0.20 & 3.20 & 20 & 18.95 & 1.06 \\
\hline E15 & 50 & 2.51 & 3.00 & 1.19 & 1.00 & 0.25 & 8.70 & 7 & 17.6 & 0.40 \\
\hline E16 & 10 & 3.80 & 4.98 & 1.31 & 2.25 & 0.45 & 12.60 & 5 & 19 & 0.26 \\
\hline & 100 & & & & & 2.40 & 11.60 & 2 & 14 & 0.14 \\
\hline E17 & 65 & 1.20 & 0.97 & 0.81 & 0.70 & 0.50 & 2.80 & 6 & 7.2 & 0.83 \\
\hline
\end{tabular}

\section{MACIÇO DE ANTAS-MATANÇA}

A análise da população total de juntas desse maciço mostra a existência de dois sistemas predominantes de direções: $40-50^{\circ}$ e $150-160^{\circ}$; os mergulhos das superfícies de juntas dos dois sistemas e demais superfícies observadas são, na maioria, subverticais. No sistema $40-50^{\circ}$, existe uma tendência dos mergulhos para o quadrante NW (figura 5). Verifica-se uma terceira família com direção aproximada E-W, que está, sobretudo, relacionada com a ocorrência de veios e filões de orientação similar. Existe alguma dispersão no diaclasamento segundo a direção NE.

As orientações de falhas mais freqüentemente observadas são $205^{\circ}: 80^{\circ}$ a subvertical e $90^{\circ}:$ : 75-85․ Verificam-se ainda algumas falhas de orientação NW, subverticais.

O sistema $40-50^{\circ}$ ocorre em $64 \%$ das estações, o que evidencia a sua persistência em toda a área estudada (quadro 3).

A principal direção de fractura corresponde, em princípio, à superfície de partição mais favorável da rocha e, portanto, à orientação que o desmonte deverá seguir.

Apesar de uma relativa homogeneidade em nível regional, existe heterogeneidade na distribuição das fracturas, mesmo em pequena escala, como se constata na análise dos diagramas das estações individuais.

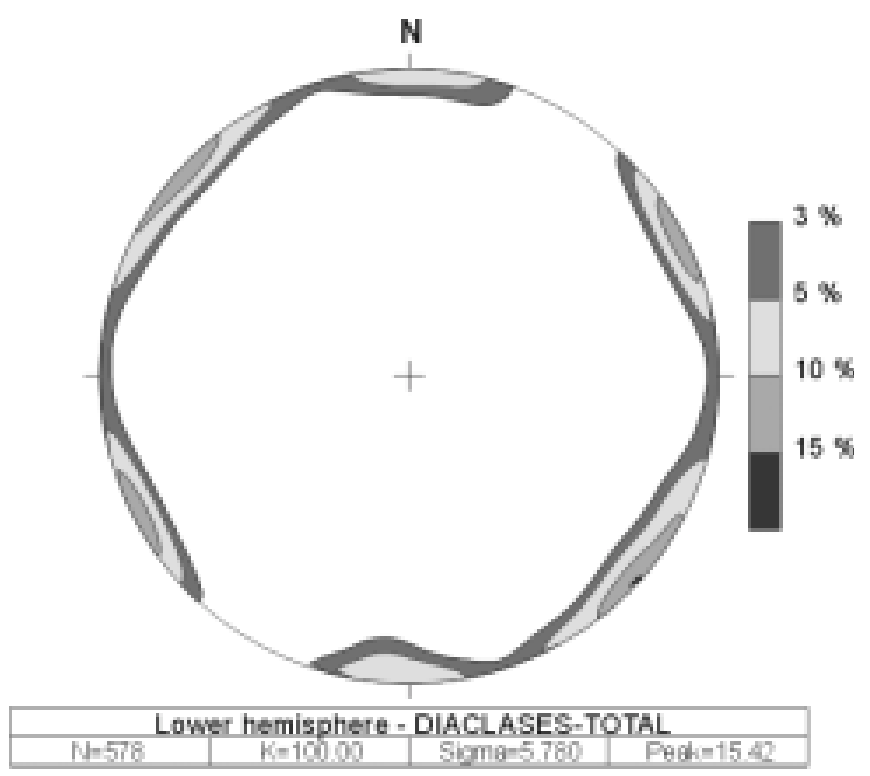

Figura 5: Estereograma dos dados obtidos em todas as estações de AntasMatança. Diagrama de contornos de densidade (rede de Schmidt - hemisfério inferior). Contornos a 3-5-10-15\%. Distribution of fracturing data in the AntasMatança massif. Density contour diagram for the poles of all the measured fracture planes (Schmidt net, lower hemisphere projection). Contours at 3-5-10$15 \%$ intervals. 
Os histogramas de freqüência dos espaçamentos entre juntas, observados nos dois sistemas principais (figura 6A e B), permitem concluir que os espaçamentos são majoritariamente reduzidos, pois há fracturas que possuem espaçamento menor do que $1 \mathrm{~m} e$ correspondem a cerca de $65 \%$ do total. Em conseqüência, o sistema $40-50^{\circ}$, principalmente, penaliza algumas áreas (figura 6A).

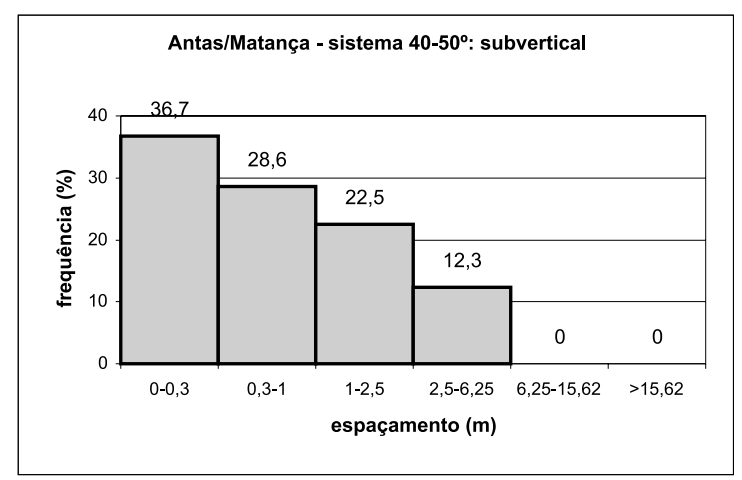

A

Figuras 6: A) e B) Histogramas de freqüência dos espaçamentos entre juntas, relativos aos dois sistemas principais observados no maciço de Antas-Matança. A) and B) frequency histogram of the spacing between joints, in the two main joint systems observed in the AntasMatança massif.
A orientação relativa entre os sistemas de fracturas é um fator igualmente importante, com a situação mais favorável, ocorrendo quando existem dois sistemas principais ortogonais subverticais e um horizontal. Com relação aos sistemas subortogonais, nenhuma das estações apresenta situação ideal. A estação 15 (figura 14) é aquela onde a orientação se mostra mais desfavorável, com um ângulo de cerca de $20^{\circ}$ entre os sistemas principais (figura 7 ).

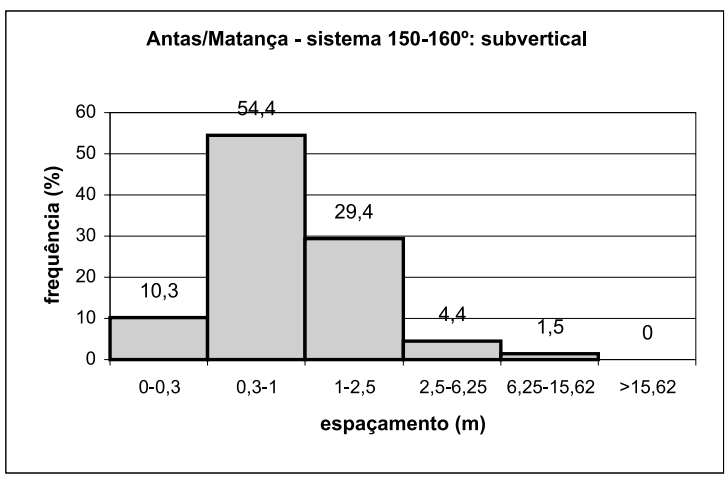

B

Quadro 3: Sistemas de fracturas observados na região de Antas-Matança. Espaçamento das fracturas em cada sistema: $\left(\mathbf{m}_{\mathbf{a}}\right)$ média aritmética, mediana, valor mínimo e máximo observados. (N) número de medidas inventariadas. Nas estações onde houve impossibilidade de verificar os espaçamentos, foram registradas apenas as atitudes das fracturas. (1) Valores de espaçamento corrigidos. (*) A família corresponde a um cluster. Table 3. Joint systems in the Antas-Matança geological stations where fracturing data was collected. Spacing between joints in each system: $\left(\boldsymbol{m}_{a}\right)$ arithmetic average, median, minimum and maximum observed value. ( $\left.\mathbf{N}\right)$ number of data. In the stations where spacing could not be observed, only joint attitude was registered. (1) Corrected spacing values. * The joint system is a cluster.

\begin{tabular}{|c|c|c|c|c|c|c|c|c|}
\hline \multirow[t]{2}{*}{ Estação } & \multirow{2}{*}{$\begin{array}{l}\text { Sistemas } \\
\text { principais }\end{array}$} & \multicolumn{5}{|c|}{ Espaçamento (m) } & \multicolumn{2}{|c|}{ Sistemas secundários } \\
\hline & & $\mu_{\mathrm{a}}$ & mediana & mínimo & máximo & $\mathbf{N}$ & & \\
\hline A1 & $35-50 ; 90$ & & & & & & $100-110 ; 90$ & $145-160 ; 90$ \\
\hline \multirow[t]{2}{*}{ A2I } & $200-205 ; 80(1)$ & 1,95 & 0,65 & 0,09 & 8,35 & 13 & & \\
\hline & $270-280 ; 85$ & 1,57 & 1,00 & 0,80 & 3,20 & 9 & & \\
\hline \multirow[t]{2}{*}{ A5I } & $35-45 ; 85-90$ & 0,93 & 0,80 & 0,10 & 2,45 & 11 & & \\
\hline & $145-160 ; 90$ & 0,73 & 0,55 & 0,25 & 1,35 & 10 & & \\
\hline \multirow[t]{2}{*}{ A6I } & $150-160 ; 90(1)$ & 1,17 & 0,60 & 0,15 & 5,10 & 17 & $170-180 ; 80-90$ & $230-245 ; 80$ \\
\hline & & & & & & & 190-200; $85\left(^{*}\right)$ & $80-90 ; 90$ \\
\hline \multirow[t]{2}{*}{ A7I } & $145-160 ; 90(1)$ & 0,77 & 0,77 & 0,15 & 1,55 & 23 & $300-310 ; 80$ & \\
\hline & $210-225 ; 80$ & 1,06 & 0,95 & 0,50 & 2,95 & 12 & & \\
\hline \multirow[t]{2}{*}{ A8I } & $25-40 ; 90$ & 0,68 & 0,50 & 0,10 & 2,80 & 28 & & \\
\hline & $150-160 ; 90$ & 2,00 & 1,95 & 1,50 & 2,60 & 6 & & \\
\hline \multirow[t]{2}{*}{ A9 } & $40-50 ; 90$ & & & & & & $80-90 ; 90$ & \\
\hline & $140-155 ; 90$ & & & & & & & \\
\hline \multirow[t]{2}{*}{ A10l } & $10-30 ; 90$ (1) & 1,18 & 0,33 & 0,11 & 6,82 & 12 & $105-120 ; 90$ & \\
\hline & $140-150 ; 90$ (1) & 2,00 & 1,00 & 0,40 & 5,60 & 5 & $30-50 ; 90$ & \\
\hline
\end{tabular}




\begin{tabular}{|c|c|c|c|c|c|c|c|c|}
\hline A12I & $\begin{array}{l}155-170(1) \\
140-150(1) \\
40-50\left(^{*}\right)\end{array}$ & $\begin{array}{l}2,42 \\
5,00 \\
0,74\end{array}$ & $\begin{array}{l}1,50 \\
3,54 \\
0,17\end{array}$ & $\begin{array}{l}0,10 \\
0,18 \\
0,09\end{array}$ & $\begin{array}{l}9,70 \\
8,43 \\
5,28\end{array}$ & $\begin{array}{l}15 \\
9 \\
14\end{array}$ & & \\
\hline A13 & $\begin{array}{l}40-60 ; 90 \\
145-160 ; 90\end{array}$ & & & & & & $110-120$ & \\
\hline A14I & $40-50 ; 90$ & 0,61 & 0,45 & 0,08 & 1,75 & 17 & & \\
\hline A15I & $\begin{array}{l}40-55 ; 90 \\
80-90 ; 85-90\end{array}$ & 2,91 & 2,15 & $\begin{array}{l}1,90 \\
1,90 \\
\end{array}$ & $\begin{array}{l}5,45 \\
9,50 \\
\end{array}$ & $\begin{array}{l}6 \\
4\end{array}$ & & \\
\hline A16 & $\begin{array}{l}60-70 ; 90 \\
150-170 ; 70-80\end{array}$ & & & & & & $90-95 ; 80$ & \\
\hline A18I & $\begin{array}{l}270-280 ; 75-80 \\
0-15 ; 80-90 \\
\end{array}$ & $\begin{array}{l}1,41 \\
2,99\end{array}$ & $\begin{array}{l}1,17 \\
3,65\end{array}$ & $\begin{array}{l}0,10 \\
0,10\end{array}$ & $\begin{array}{l}5,40 \\
5,30 \\
\end{array}$ & $\begin{array}{l}30 \\
7 \\
\end{array}$ & $\begin{array}{l}305-310 ; 80 \\
140-150 \\
\end{array}$ & $300 ; 40$ \\
\hline A19 & $\begin{array}{l}40-60 ; 90 \\
150-160 ; 90 \\
\end{array}$ & & & & & & $\begin{array}{l}0-10 ; 90 \\
90-100 \\
\end{array}$ & \\
\hline A21 & $200-210 ; 70-85$ & & & & & & $80-90 ; 80-90$ & \\
\hline A221 & $\begin{array}{l}100-110 ; 75-85 \\
80-90 ; 90 \\
40-55 ; 90(1) \\
150-165 ; 90(1)\end{array}$ & $\begin{array}{l}5,26 \\
1,02 \\
1,36 \\
1,89 \\
\end{array}$ & $\begin{array}{l}2,75 \\
0,67 \\
1,05 \\
1,03 \\
\end{array}$ & $\begin{array}{l}0,70 \\
0,17 \\
0,18 \\
0,41 \\
\end{array}$ & $\begin{array}{l}24,45 \\
2,37 \\
4,16 \\
7,07\end{array}$ & $\begin{array}{l}11 \\
9 \\
8 \\
9\end{array}$ & & \\
\hline A23I & $\begin{array}{l}70-90 ; 90 \\
160-170 ; 90\end{array}$ & 4,20 & 5,15 & 0,50 & 6,00 & 6 & $\begin{array}{l}10-20\left(^{*}\right) \\
40-50 ; 80-90\end{array}$ & \\
\hline A24I & $\begin{array}{l}160-170 \\
40-50 ; 90 \\
0-10 ; 90\end{array}$ & $\begin{array}{l}3,17 \\
2,58\end{array}$ & $\begin{array}{l}3,18 \\
3,20\end{array}$ & $\begin{array}{l}1,80 \\
0,35\end{array}$ & $\begin{array}{l}4,35 \\
3,55\end{array}$ & $\begin{array}{l}6 \\
6 \\
2 \\
\end{array}$ & $\begin{array}{l}90-100 \\
140-150\end{array}$ & \\
\hline A25I & $95-105$ (1) & 1,22 & 1,06 & 0,24 & 3,56 & 13 & $140-150$ & \\
\hline A26 & $\begin{array}{l}30-40 \\
150-170\end{array}$ & & & & & & & \\
\hline A27 & $30-50$ & & & & & & $90-110$ & $130-140$ \\
\hline
\end{tabular}

Quadro 4: Distribuição estatística dos dados coletados na região de Antas-Matança. $\left(\mathrm{m}_{\mathrm{a}}\right)$ média aritmética, (DP) desvio padrão, (CV) coeficiente de variação, mediana, $(\mathrm{N})$ número de intersecções, $(\mathrm{L})$ comprimento da scan-line, (fF) freqüência da fracturação. * Valores de espaçamento corrigidos. Table 4. Statistical distribution of scan lines data in Antas-Matança. ( $\boldsymbol{m}_{\mathbf{a}}$ ) arithmetic average, $(D P)$ standard deviation, (CV) variation coefficient, median, $(N)$ intersection number, $(L)$ scan line width, (fF) fracturing frequency.

${ }^{*}$ Corrected spacing values.

\begin{tabular}{|l|l|l|l|l|l|l|l|l|l|l|}
\hline Estação & Azimute & \multicolumn{1}{|c|}{$\mu_{\mathbf{a}}$} & \multicolumn{1}{|c|}{ DP } & \multicolumn{1}{|c|}{ CV } & Mediana & Mínimo & Máximo & \multicolumn{1}{|c|}{ N } & \multicolumn{1}{|c|}{ L } & \multicolumn{1}{|c|}{ fF } \\
\hline A2I & 0 & 1,57 & 0,99 & 0,63 & 1 & 0,8 & 3,2 & 8 & 11 & 0,73 \\
\hline & $90^{*}$ & 2,16 & 2,63 & 1,22 & 0,83 & 0,09 & 6,5 & 12 & 25,6 & 0,47 \\
\hline A5I & 325 & 0,93 & 0,68 & 0,73 & 0,8 & 0,1 & 2,45 & 10 & 8,35 & 1,20 \\
\hline & 50 & 0,64 & 0,4 & 0,63 & 0,55 & 0,25 & 1,35 & 10 & 5,8 & 1,72 \\
\hline A6la & 0 & 4,8 & 4,77 & 0,99 & 3,75 & 0,15 & 13,35 & 6 & 28,8 & 0,21 \\
\hline & $90^{*}$ & 8,84 & 9,39 & 1,06 & 8,84 & 2,2 & 15,48 & 3 & 18,3 & 0,16 \\
\hline A6lb & $90^{*}$ & 1,76 & 2,13 & 1,21 & 1,31 & 0,25 & 9,45 & 19 & 32,1 & 0,59 \\
\hline & $0^{*}$ & 2,34 & 1,79 & 0,76 & 2,24 & 0,36 & 6,12 & 8 & 20,7 & 0,39 \\
\hline A6lc & 70 & 0,88 & 0,73 & 0,83 & 0,6 & 0,1 & 2,7 & 16 & 13,2 & 1,21 \\
\hline A6ld & 0 & 1,3 & 0,92 & 0,71 & 1,15 & 0,4 & 2,85 & 6 & 6,5 & 0,92 \\
\hline & 90 & 0,74 & 0,62 & 0,84 & 0,47 & 0,1 & 1,71 & 9 & 5,95 & 1,51 \\
\hline A7la & 325 & 1,06 & 0,7 & 0,66 & 0,95 & 0,5 & 2,95 & 11 & 10,6 & 1,04 \\
\hline
\end{tabular}


LISBOA, J. V.; OLIVEIRA, D. P. S. Maciços graníticos de Esmolfe e Antas - Matança...

\begin{tabular}{|c|c|c|c|c|c|c|c|c|c|c|}
\hline & 48 & 0,76 & 0,4 & 0,53 & 0,7 & 0,35 & 1,55 & 17 & 12,2 & 1,39 \\
\hline A7lb & $15^{*}$ & 1,28 & 1,54 & 1,20 & 0,74 & 0,11 & 5,6 & 13 & 17,4 & 0,75 \\
\hline \multirow[t]{2}{*}{ A8I } & 305 & 0,68 & 0,56 & 0,82 & 0,5 & 0,1 & 2,8 & 27 & 17,55 & 1,54 \\
\hline & $20^{*}$ & 1,02 & 0,36 & 0,35 & 1,05 & 0,42 & 1,53 & 7 & 8 & 0,88 \\
\hline A10la & 50 & 2,9 & 1,94 & 0,67 & 2,5 & 0,6 & 6,6 & 8 & 23,2 & 0,34 \\
\hline \multirow[t]{2}{*}{ A10lb } & 352 & 1,57 & 1,15 & 0,73 & 1,5 & 0,4 & 3,95 & 15 & 23,6 & 0,64 \\
\hline & $270^{*}$ & 0,9 & 1,11 & 1,23 & 0,38 & 0,11 & 3,7 & 10 & 10,1 & 0,99 \\
\hline A12la & $30^{*}$ & 4,06 & 4,08 & 1,00 & 1,81 & 0,18 & 10,51 & 10 & 44 & 0,23 \\
\hline \multirow[t]{2}{*}{ A12lb } & $20^{*}$ & 1,32 & 1,15 & 0,87 & 0,9 & 0,06 & 4,89 & 17 & 32,7 & 0,52 \\
\hline & $100^{*}$ & 2,02 & 3,35 & 1,66 & 0,24 & 0,09 & 10 & 13 & 25,3 & 0,51 \\
\hline \multirow[t]{2}{*}{ A12lc } & 165 & & & & & 2,9 & 9,8 & 2 & 12,7 & 0,16 \\
\hline & 75 & & & & & 5,3 & 9,2 & 2 & 14,5 & 0,14 \\
\hline A14I & 325 & 0,86 & 0,88 & 0,89 & 0,7 & 0,15 & 3,15 & 17 & 14,7 & 1,16 \\
\hline \multirow[t]{2}{*}{ A15I } & 52 & 6,6 & 2,51 & 0,38 & 6,65 & 3,5 & 9,6 & 4 & 26,4 & 0,15 \\
\hline & 140 & 2,5 & 2,05 & 0,82 & 2,28 & 0,3 & 6,2 & 9 & 22,5 & 0,40 \\
\hline \multirow[t]{4}{*}{ A18I } & 95 & 1,05 & 0,83 & 0,79 & 0,8 & 0,1 & 2,65 & 17 & 16,8 & 1,01 \\
\hline & 8 & 0,88 & 0,53 & 0,6 & 0,85 & 0,1 & 2,15 & 25 & 21,1 & 1,18 \\
\hline & 20 & 1,44 & 0,92 & 0,64 & 1,3 & 0,2 & 3,3 & 18 & 24,5 & 0,73 \\
\hline & 110 & 3,41 & 4,37 & 1,28 & 0,6 & 0,1 & 11,6 & 8 & 23,9 & 0,33 \\
\hline \multirow[t]{2}{*}{ A221 } & 0 & 2,66 & 2,72 & 1,02 & 1,95 & 0,17 & 12,06 & 24 & 61,2 & 0,39 \\
\hline & $90^{*}$ & 1,25 & 1,41 & 1,13 & 0,85 & 0,1 & 5,3 & 22 & 29 & 0,76 \\
\hline \multirow[t]{2}{*}{ A23I } & 5 & 3,3 & 2,71 & 0,82 & 2,9 & 0,2 & 8,6 & 10 & 33 & 0,30 \\
\hline & 90 & 2,53 & 2,62 & 1,04 & 1,93 & 0,25 & 8,7 & 9 & 20,2 & 0,45 \\
\hline \multirow[t]{2}{*}{ A24la } & 330 & 6,4 & 6,46 & 1,01 & 3,6 & 1 & 17 & 5 & 32 & 0,16 \\
\hline & $70^{*}$ & 4,13 & 2,99 & 0,72 & 3,2 & 1,72 & 10,5 & 8 & 30,2 & 0,26 \\
\hline \multirow[t]{2}{*}{ A24Ib } & 330 & 9,5 & 6,89 & 0,73 & 9,4 & 3,2 & 16 & 4 & 38 & 0,11 \\
\hline & 55 & 5 & 4,03 & 0,81 & 4,05 & 1,4 & 10,5 & 4 & 20 & 0,20 \\
\hline \multirow[t]{2}{*}{ A24lc } & 305 & 2,87 & 1,82 & 0,63 & 3,2 & 0,35 & 5,55 & 6 & 17,2 & 0,35 \\
\hline & 35 & & & & & 5,7 & 6,5 & 2 & 12,2 & 0,16 \\
\hline \multirow[t]{2}{*}{ A25I } & $26^{*}$ & 1,03 & 0,9 & 0,87 & 0,9 & 0,2 & 3,56 & 15 & 15 & 1,00 \\
\hline & 0 & 7,33 & 1,31 & 0,18 & 7,8 & 5,85 & 8,35 & 3 & 22 & 0,14 \\
\hline
\end{tabular}

O diaclasamento suborizontal apresenta espaçamento muito variável, desde $30 \mathrm{~cm}$ (Abrocedo) até mais de $5 \mathrm{~m}$ (Antas, figura 8), tendendo sempre a aumentar com a profundidade.

\section{DISCUSSÃO}

No maciço de Esmolfe, os melhores locais de fracturação (espaçamento, tipo de fractura, orientação) observados, encontram-se na área das estações E16, E5, E6 e E7 (figura 13).

As estações E6 e E7, particularmente, evidenciam a existência de juntas com espaçamento reduzido alternando-se com espaçamentos muito amplos a extremamente amplos (ver classificação na figura 4.B). Esta tendência (quadro 2) é demonstrada por fortes assimetrias positivas das distribuições (média $>>$ mediana).

Noutros locais, referidos no ponto "Áreas com interesse para extração de pedra ornamental" e assinalados na figura 13, observam-se espaçamentos entre fracturas dentro do intervalo amplo ou superior a este (figura 4B), porém o padrão de afloramento impediu o traçado de linhas.

No maciço de Antas-Matança (figura 14), embora globalmente sejam irregulares os espaçamentos nos sistemas de juntas (quadro 3) e, conseqüentemente, tam- 


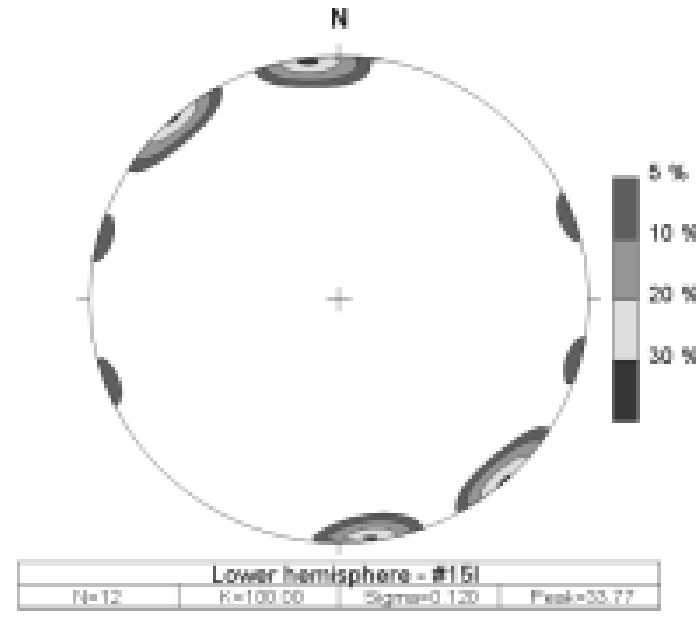

Figura 7: Diagrama de contornos de densidade relativo aos polos das fracturas na estação A15 (rede de Schmidt - hemisfério inferior). Contornos a 5-10-15$20-30 \%$.

Density contour diagram for the poles of all the measured fracture planes in geological station A15 (Schmidt net, lower hemisphere projection). Contours at 5-10-15-20-30\% intervals.

bém as distâncias entre fracturas ao longo das scanlines (quadro 4), é possível constatar que as áreas correspondentes às estações $A 24, A 15, A 12, A 6$ e $A 23$ (figura 14; quadro 4), são aquelas que respectivamente apresentam maiores distâncias.

Nomeadamente, na estação A24 (figura 14; quadro 4), onde no conjunto dos perfis se observam as maiores distâncias médias, três dos quais apresentam as menores freqüências de fracturação registradas. Os elevados desvios-padrão são devidos à amplitude das distâncias. Porém, se forem considerados os valores de dispersão relativa, estes evidenciam a tendência de distâncias amplas entre fracturas. O perfil A24lc, $305^{\circ}$ (quadro 4) apresenta assimetria negativa da distribuição (mediana > média), indicando assim que os espaçamentos maiores são mais comuns.

Na estação A15I (figura 14; quadro 4), as distribuições são praticamente simétricas, com freqüência de fracturação reduzida, refletindo confiança no valor da média. A estação A23I (figura 14; quadro 4), embora com menores distâncias médias entre fracturas, apresenta também razoável simetria da distribuição.

$\mathrm{Na}$ estação A6I, perfil A6la, $90^{\circ}$ (figura 14; quadro 4), com elevado desvio-padrão, outros parâmetros (coeficiente de variação, mediana e freqüência de fracturação) confirmam o valor médio, evidenciando que as distâncias entre fracturas são majoritariamente elevadas.

A forte assimetria positiva da distribuição do perfil A12lb, $100^{\circ}$ (figura 14 ; quadro 4 ), onde se verifica uma mediana muito baixa, evidencia a ocorrência de clusters de fracturas muito próximos; em contrapartida, a dispersão relativamente alta em conjunto com freqüência de fracturação baixa, indica ocorrência de espaçamentos amplos (classificação na figura 4B), a que se deve o valor da média aritmética.

Este espaçamento tende a aumentar com a profundidade, como pode ser observado numa das pedreiras de Antas (Incoveca), onde o espaçamento médio entre as fracturas, em duas das frentes do piso mais profundo em laboração, é de 4 m (figura 8).

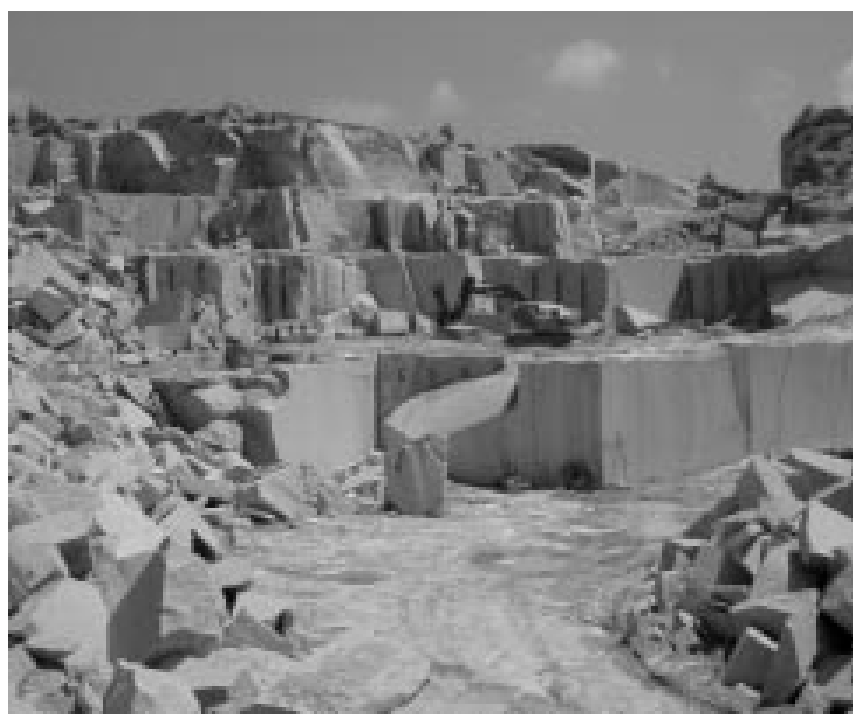

Figura 8: Aspecto geral da pedreira da Incoveca, em Antas. Notar a diminuição da densidade de fracturação do topo para a base da pedreira, onde há quase ausência de fracturas. General aspect of the Incoveca quarry in Antas. Notice the decrease in fracturing density from the surface to the bottom of the quarry, with handly any fractures.

Comparando os intervalos de classe propostos, verifica-se que a sua distribuição é relativamente similar em Antas-Matança e Esmolfe, predominando os espaçamentos reduzidos (0.3-1m). No entanto, comparando-se a freqüência das distâncias médias entre fracturas nas scan-lines, no conjunto o diaclasamento em Esmolfe parece ser ligeiramente mais espaçado do que em Antas-Matança, como pode ser observado no histograma da figura 9B. Este fato deve-se, fundamentalmente, à freqüência de espaçamentos muito reduzidos $(0-0,3 \mathrm{~m})$ no maciço de Antas-Matança, que baixam as distâncias médias entre as fracturas. Em Esmolfe, num terço das linhas efetuadas, não se observam espaçamentos médios inferiores a $2 \mathrm{~m}$.

Este aspecto da fracturação é responsável, em Antas-Matança, pela maior assimetria das distribuições e menor correlação linear entre a média e a mediana. 


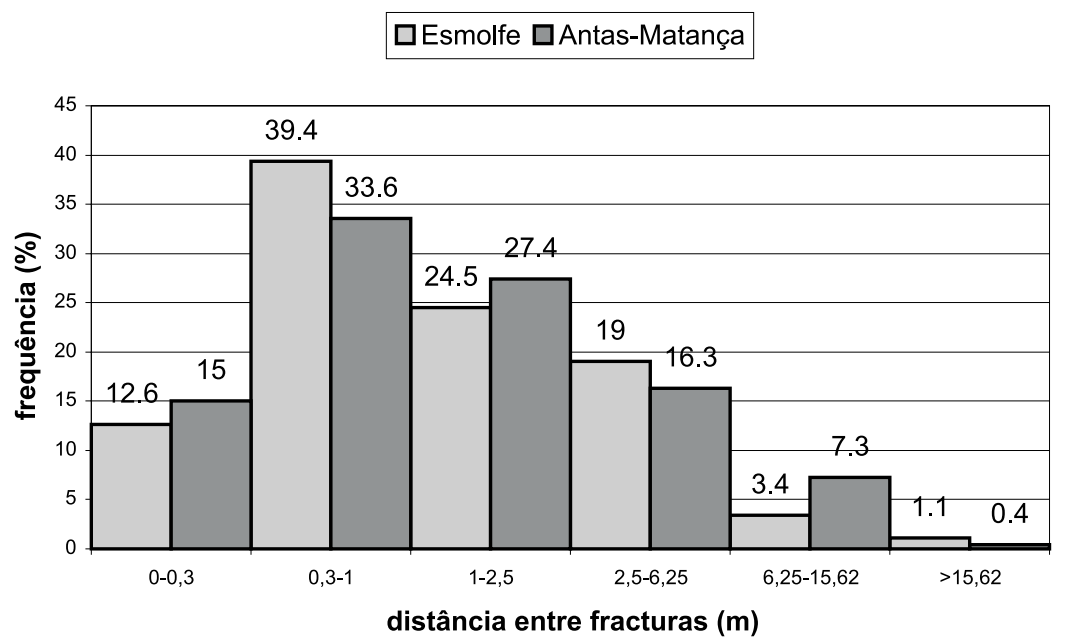

A

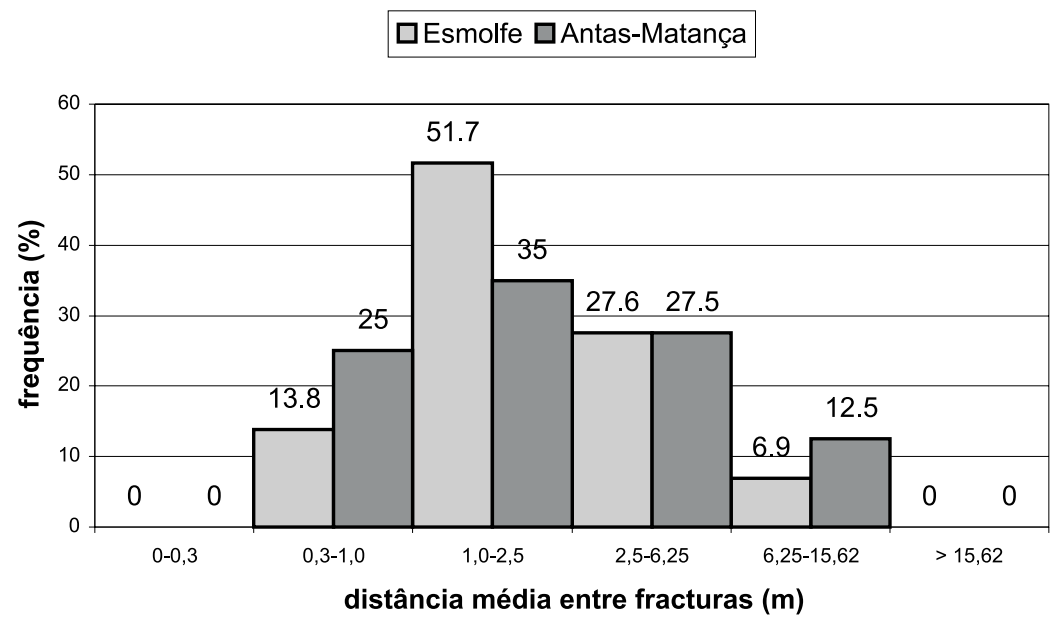

B

Figura 9: A) Histograma de freqüência das distâncias entre juntas consecutivas, em scan-lines efetuadas nos principais afloramentos, em ambos os maciços. B) Histograma de freqüência das distâncias médias entre fracturas, observadas na totalidade das scan-lines, em Esmolfe e Antas-Matança. A) Frequency histogram of distance between consecutive joints, in scan-lines carried through the major outcrops, in both massifs. B) Frequency histogram of average distance between joints, in all the scan lines carried through Esmolfe and Antas-Matança massifs.

Os intervalos de espaçamento, segundo a classificação apresentada (figura 4B), são majoritariamente moderados a amplos, em ambos os maciços.

A média das freqüências de fracturação calculada em Esmolfe $(0,64)$, também é menor que do que em Antas-Matança $(0,94)$.

No quadro 5 apresentam-se as áreas médias entre as fracturas, nas estações de ambos os maciços, que satisfazem as condições referidas anteriormente para a determinação deste parâmetro. O erro associado ao cálculo da área média é elevado, possibilitando apenas uma vaga estimativa do seu valor; no entanto, as áreas observadas em estações como a E16 e A24lc confirmam o potencial daqueles locais. Considerando-se que os espaçamentos entre as fracturas suborizontais são, em geral, superiores a $1,5 \mathrm{~m}$, o bloco natural obtido naquelas áreas atinge freqüentemente dimensões superiores a 20 $\mathrm{m}^{3}$. 
$5 \mathrm{~A}$

\begin{tabular}{|l|l|l|}
\hline Estação & Azimutes & Amed \\
\hline E16 & $10 ; 100$ & 26,60 \\
\hline
\end{tabular}

\section{$5 B$}

\begin{tabular}{|l|l|l|}
\hline \multicolumn{1}{|c|}{ Estação } & Azimutes & \multicolumn{1}{c|}{ Amed } \\
\hline A2I & $0 ; 90$ & 3,39 \\
\hline A5I & 325,50 & 0,6 \\
\hline A6Id & $0 ; 90$ & 0,96 \\
\hline A7la & $325 ; 48$ & 0,81 \\
\hline A12lb & $20 ; 100$ & 2,67 \\
\hline A18I & $20 ; 110$ & 4,9 \\
\hline A24lc & $305 ; 35$ & 17,5 \\
\hline
\end{tabular}

Quadro 5: Produto das médias dos espaçamentos entre fracturas (Amed) em scan-lines ortogonais ou subortogonais entre si; A) maciço de Esmolfe, B) maciço de Antas-Matança. Table 5. Product of the average spacing between fractures (Amed) in orthogonal or sub-orthogonal scan lines; A) Esmolfe massif, B) Antas-Matança massif.

\section{ATIVIDADE EXTRATIVA}

\section{MACIÇO DE ESMOLFE}

O granito deste maciço, embora texturalmente homogêneo, apresenta, no que se refere à cor, pequenas variações macroscópicas. Verificam-se, em algumas áreas, entre os vértices geodésicos (v.g.) de Santo lldefonso e Pedras Altas, pedreiras onde a tonalidade mais escura do granito é devida a cor acinzentada do feldspato.

A rocha aflora geralmente em penedos, cuja dimensão permite, por vezes, a instalação de pedreiras (figura 10). A espessura do manto de intemperismo é, em geral, inferior a $20 \mathrm{~cm}$.

Este granito é comercializado sob várias designações, com a Cinza, sendo a mais comum.

Ao longo do vale da ribeira de Sezures, numa faixa de orientação aproximada NE, a escassez dos afloramentos se deve à cobertura aluvionar e à maior espessura do manto de intemperismo. Isto também ocorre ao longo de uma faixa que se prolonga para SW de Sezures até ao rio Dão, à exceção do extremo SW (estação E16).

Cabe ainda mencionar a existência de uma antiga explotação mineira, em filões, no vale da ribeira de Sezures (figura 13).

As características físico-mecânicas deste granito sugerem sua utilização tanto em decoração de interiores quanto em revestimento de exteriores (MOURA et al., 1983).

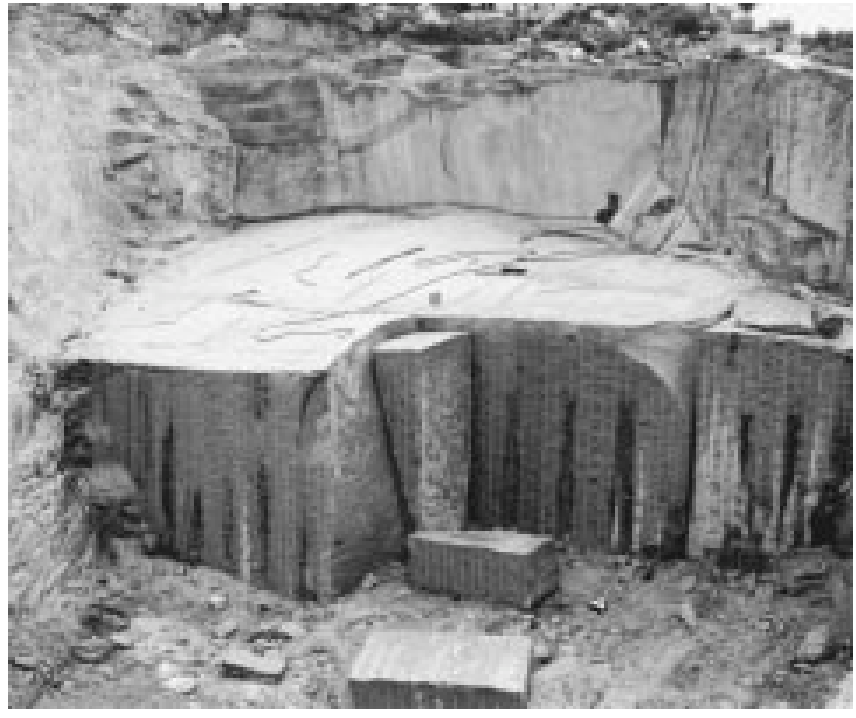

Figura 10: Pedreira no bordo SW do maciço de Esmolfe. Notar a zona de intemperização côncava ao fundo, que constitui o limite da pedreira. Quarry in the SW border of the Esmolfe massif. Note the concave weathering layer, which is the

\section{Estado atual de explotação do maciço}

No maciço de Esmolfe, verifica-se uma profusão de pequenas pedreiras (figura 13), como já tinha sido observado por Moura et al. (1996). Devido à morfologia dos afloramentos e à ausência de planeamento, a extração resume-se, na maior parte das vezes, ao aproveitamento dos penedos superficiais, não existindo qualquer critério baseado em estudos geológico-mineiros, para a explotação adequada daquelas pedreiras.

Presentemente, o núcleo principal da atividade concentra-se numa faixa de orientação NE, ao longo de uma encosta de declividade suave, exposta a SE, entre o rio Côja e a ribeira de Sezures. Na encosta exposta a NW, de maior declive, existem apenas pedreiras nas imediações da Ponte do Ferreira. Isto deve-se à existência de um caos de blocos, com condições de desmonte menos favorável do que a encosta a SE. Apenas nas duas principais pedreiras, são extraídas pedras para bloco. Nas demais, extraem-se pedras para cubos.

A outra área de incidência das explotações, também com orientação NE, situa-se entre os v.g. de Santo Ildefonso e Pedras Altas. Aqui, todas as pedreiras de pequenas dimensões estão em flanco de encosta com declive acentuado. A pedra extraída destina-se unicamente à produção de cubos e lancis, apesar das boas condições, existentes em alguns locais para a extração de blocos. 


\section{Principais problemas observados}

Os principais problemas que se colocam à atividade extrativa, tal como em Antas-Matança, são relacionados com a fracturação e o padrão de afloramento da rocha em penedos ou "bolas". Estes, por vezes, são parcialmente aflorantes e encontram-se geralmente pouco fracturados, sendo limitados lateralmente e, em profundidade, por uma zona de alteração de espessura variável. Relacionam-se também com um padrão de exfoliação esferoidal - disjunção em "bolas", que prejudica a extração de blocos.

A freqüência das juntas, por vezes, elevada e sem padrões regulares, juntamente com seu mergulho, são também fatores desfavoráveis.

A alteração, sobretudo da biotite, provoca o aparecimento de manchas castanhas na rocha devido à oxidação do ferro. Esta alteração é mais freqüente na presença de schlieren.

É comum que se observem manchas ferruginosas ao longo das juntas de exfoliação e na zona superior e inferior dos níveis interjuntas suborizontais superficiais (sheets), devido à alteração de minerais que contêm ferro na sua estrutura. Em alguns locais, verifica-se um crescimento concêntrico destas manchas, na rocha segmentada por juntas. Em todos os casos, as manchas tendem a diminuir com a profundidade. A origem deste fenômeno é duvidosa, podendo estar relacionada com a circulação de água nas fracturas.

\section{Áreas com interesse para a extração de pedra ornamental ou industrial}

As áreas com maior potencial localizam-se em relevos de orientação ENE a NE, a norte e sul da ribeira de Sezures. Na figura 13 estão assinaladas estas áreas.

- Afloramentos a norte de Vale Amoso: a área das estações E5 e E6, com várias cavas a céu aberto, são aquelas onde se verificam maiores espaçamentos entre as fracturas (de amplos a muito amplos, ver quadro 2);

- Vertente sul da Ribeira de Côja: corresponde a uma região de afloramentos que se prolonga desde o bordo N, para SW, até o bordo W do maciço, onde existem algumas pedreiras (área das estações E7, E9 e E12). Em grande parte desta região não existem atividades de lavra e não foram obtidos dados devido ao caos de blocos superficiais; no entanto, os espaçamentos observados são majoritariamente moderados e, subordinadamente, amplos. Nestas estações, os espaçamentos são freqüentemente amplos a muito amplos. Na estação E9, o bloco natural atinge volumes de $14 \times 5 \times 2,5 \mathrm{~m}$.

$O$ potencial desta zona relaciona-se diretamente com a dimensão dos penedos, os quais, quando a fracturação é escassa, permitem, por vezes, a instalação de pedreiras;

- Área de Tapada do Monte: nas estações E14 e E15, embora se verifique uma boa continuidade dos afloramentos, estes estão próximos da ribeira e existem clusters com espaçamento reduzido a moderado;

- Área de Pedras Altas: toda a área, desde as imediações do v.g. de Pedras Altas para S deste, ao longo de uma faixa de orientação NE-SW, apresenta boas potencialidades os espaçamentos médios obtidos nas estações E1, E2 e E3 estão no intervalo moderado, mas como foram observados à superfície, esperam-se valores meIhores abaixo das fracturas de escamação superficiais. Além disso, devido às condições de exposição da rocha na estação $\mathrm{E} 10$, os valores obtidos são bastante inferiores aos espaçamentos que efetivamente se podem obter na pedreira.

A estreita faixa de granito entre Sezures e o rio Dão, com orientação NNE, não tem afloramentos significativos, estando grande parte da área ocupada por terreno agrícola. Apenas verifica-se a ocorrência de um afloramento importante a sul de Campina, com espaçamentos médios, amplos a muito amplos. Este afloramento está em contato com o granito porfirítico de granulação grosseira, que transiciona gradualmente para aquele.

\section{MACIÇO DE ANTAS-MATANÇA}

O granito deste maciço apresenta uma tonalidade cinzento-azulada, que é um pouco mais escura do que a do granito de Esmolfe. Texturalmente apresenta também pequenas diferenças, como uma leve tendência porfirítica. À escala do maciço, o granito mostra-se homogêneo, embora na região de Matança seja mais escuro (figura 2B2).

É comercializado sob a designação de Cinza ou Cinzento Antas.

Em alguns locais, ocorre uma fácies granítica de tonalidade cinzento-amarelada e aspecto homogêneo. Esta variedade, cujas características são devidas à alteração, tem espessura geralmente reduzida e é controlada pela fracturação suborizontal (levantes), tendo sido explotada numa pedreira a norte do cemitério de Antas. 
A existência de afloramentos extensos, com reduzida espessura de intemperização, no flanco da encosta, cria condições favoráveis para a extração.

As características físico-mecânicas deste granito, estudadas a partir de uma amostragem na zona da estação A17, apontam para a sua utilização em interiores e em exteriores (MOURA et al., 1983).

\section{Estado atual de explotação do maciço}

A atividade extrativa atual confina-se em uma pequena área nas imediações de Antas (figura 14), onde existem seis pedreiras, das quais apenas duas, as mais importantes, se encontram em atividade. Por ocasião dos trabalhos de campo na zona de Abrocedo (Matança), uma nova pedreira encontrava-se em fase inicial de exploração.

\section{Principais problemas observados}

As principais dificuldades encontradas com a atividade extrativa relacionam-se com a densidade das fracturas, padrão da rede por elas constituído e existência de fissuras ou superfícies de fraqueza, que abrem por descompressão.

As juntas de alívio assumem importância elevada em algumas áreas deste maciço, nomeadamente na área de Abrocedo, o que implica maiores descobertas. Estas juntas manifestam-se também no padrão de afloramento, originando "capas", com formas arredondadas.

A presença de filões de aplito e quartzo (majoritariamente pequenos filões ou veios), de ocorrência agrupada e com elevada continuidade, pode inviabilizar extensas áreas. Estas ocorrências apresentam predominância segundo à direção $E-W$ e mergulhos subverticais para norte (figura 11). No entanto, o reduzido número de dados e a sua distribuição espacial próxima limitam a representatividade desta tendência. Pode-se, entretanto, concluir que se trata de uma orientação dominante, pelo menos numa faixa ENE, entre Antas e Forcadas.

Esta geração de veios sugere uma compressão máxima horizontal (eixo $z$ de maior encurtamento), paralela à direção E-W, atuante durante a sua implantação.

Um aspecto textural relevante neste maciço consiste na freqüente existência de minerais orientados, sobretudo micas, originando superfícies de fraqueza, que se abrem por descompressão, durante o desmonte da rocha (figura 12).

$\mathrm{Na}$ zona central do maciço, entre Antas, Pena e Corgas (figura 14), existiam quatro explotações mineiras em filões, sugerindo assim a existência de mineralizações

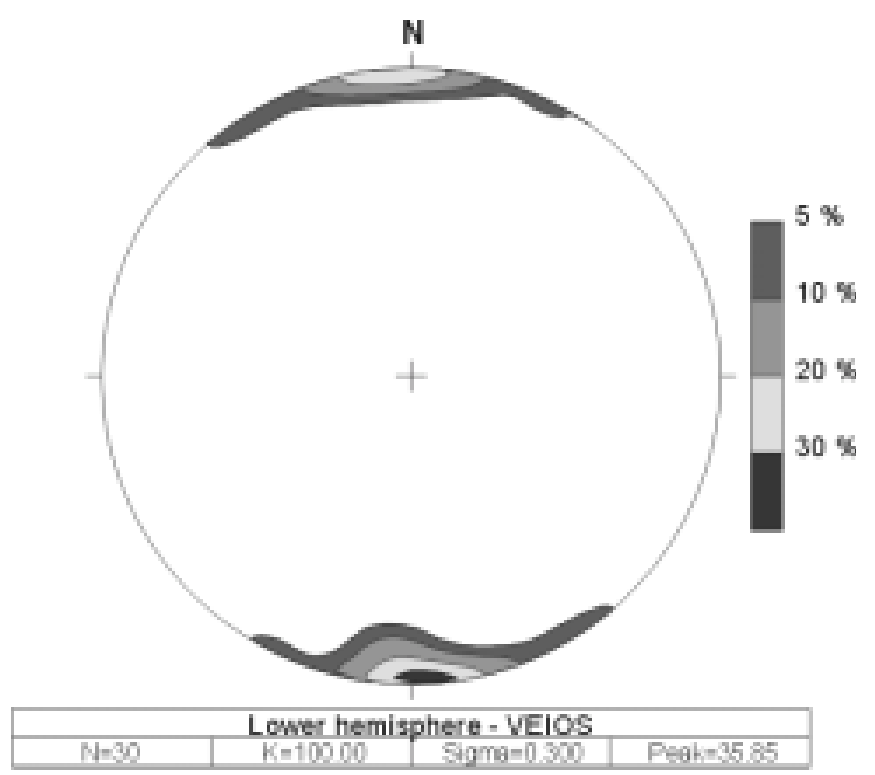

Figura 11: Estereograma dos polos das normais aos planos dos veios, em Antas-Matança (rede de Schmidt-Lambert). Contornos a 5-10-20-30\%. Density contour diagram for the poles of the entire measured vein planes in AntasMatança (Schmidt net, lower hemisphere projection). Contours at 5-10-20-30\% intervals.

na área e que, portanto, prejudicam a exploração do granito.

Os encraves ou xenólitos, conhecidos no jargão mineiro por "mulas", são raros em ambos os maciços, não constituindo defeitos significativos para sua exploração.

\section{Áreas com interesse para a extração de pedra ornamental ou industrial}

A seleção das áreas que aparentam melhor aptidão para explotação de bloco baseou-se na observação dos espaçamentos entre fracturas, na maior ou menor ocorrência de heterogeneidades, na forma de afloramento, acessibilidade, entre outros. Estas áreas são as seguintes (figura 14):

- Afloramentos ao longo da vertente da Ribeira do Carapito exposta a NW, entre Antas e Pisão: Próximo a este último, ocorrem afloramentos com elevado potencial (estação A12), conforme pode ser observado pela análise dos dados (quadros 4 e 5B);

- Afloramentos a NW de Antas até Lameira: ocorrem a cerca de $500 \mathrm{~m}$ a NW de Antas, afloramentos pouco fracturados (estações A23 e A24), porém parte deles corresponde a gran- 


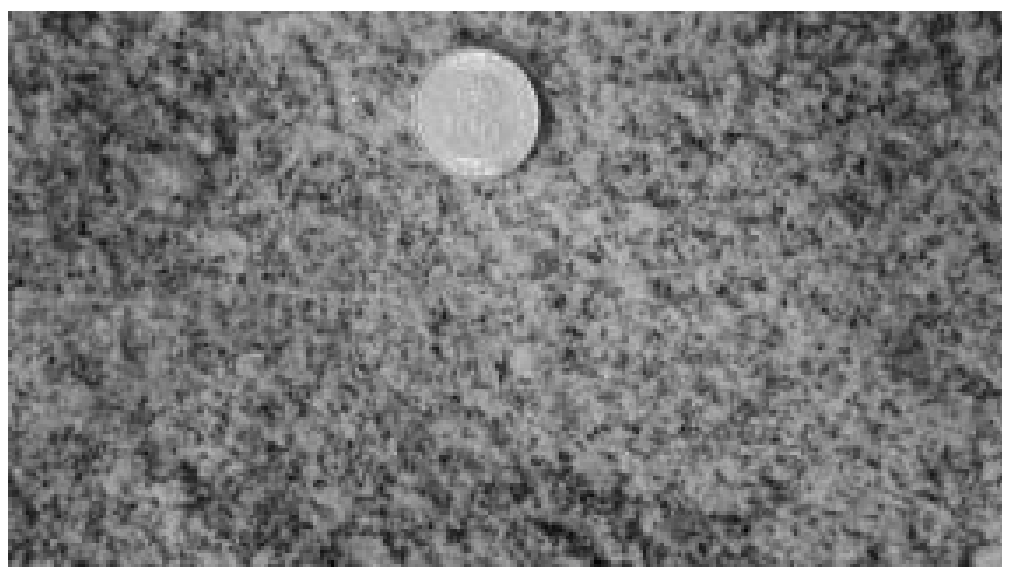

Figura 12: Descontinuidade no granito provocada por estreito veio de quartzo. As fraturas são freqüentemente causadas pelo alinhamento de minerais, em geral, micas. Alguns defeitos no granito da zona de Antas são perceptíveis, em geral, após o desmonte. Discontinuity in granite caused by thin quartz veinlet. The fissures are frequently caused by preferential mineral alignment, usually micas. This is a common defect in the granite of Antas area, most of the times imperceptible before quarrying.

des penedos, desconhecendo-se as características da rocha em profundidade;

- Área de Antas: o potencial dos afloramentos nas imediações desta aldeia pode ser verificado em duas pedreiras (A17 e A18I). Outros afloramentos encontram-se subaproveitados, com o desmonte tendo sido efetuado apenas nos níveis superficiais;

- Faixa entre Matança e Forcadas (Abrocedo), a sul da estrada que liga as duas aldeias: esta faixa corresponde a uma forma em domo alongado, onde as fracturas de alívio estão bastante desenvolvidas, definindo lajes arqueadas. $O$ espaçamento vertical entre estas juntas subhorizontais aumenta progressivamente em profundidade, desde cerca de 1 até $2 \mathrm{~m}$, a partir da $3^{\text {a }}$ ou 4를 superfície de alívio. Existem, localmente, boas áreas entre as fracturas (A6la). Contudo, esta situação não se repete em todas as estações (A6lc e A6ld);

- Afloramentos imediatamente a sul de Forcadas: junto a Forcadas, ocorre uma forma tipo nubbin (colina granítica coberta de penedos ou blocos dispersos), onde os maiores penedos já foram explotados. Esta área parece ter algum potencial, embora a fracturação à superfície seja desfavorável e ocorram estruturas filoneanas agrupadas.
O granito da fácies de Almeidinha-Fuínhas-Cortiçô, aflorante numa pequena área a oeste de Maceira, apesar de exibir textura com potencial ornamental, tem seu estado de alteração intempérica e de fracturação associado à pequena extensão dos afloramentos, o que o torna desprovido de interesse.

\section{CONCLUSÕES}

Os maciços granticos de Esmolfe e de AntasMatança caracterizam-se como granitos peraluminosos.

As características texturais destes granitos são relativamente homogêneas, embora se registrem pequenas variações.

A textura do granito de Esmolfe é mais homogênea do que a do granito de Antas-Matança, apresentando uma granulação mais grossa e cor mais clara, devido à maior dimensão dos agregados de feldspato. A alteração intempérica superficial é menor em Esmolfe.

O granito de Antas-Matança apresenta pequenas variações em termos de cor e homogeneidade do grão. Em amostras polidas, os indícios de alteração intempérica dos feldspatos são, em geral, mais perceptíveis macroscopicamente do que no granito de Esmolfe.

As características petrográficas e texturais destes granitos em apreço os potencializam como pedras ornamentais, com a fracturação constituindo-se na principal condicionante à definição de áreas com aptidão ornamental e industrial. 


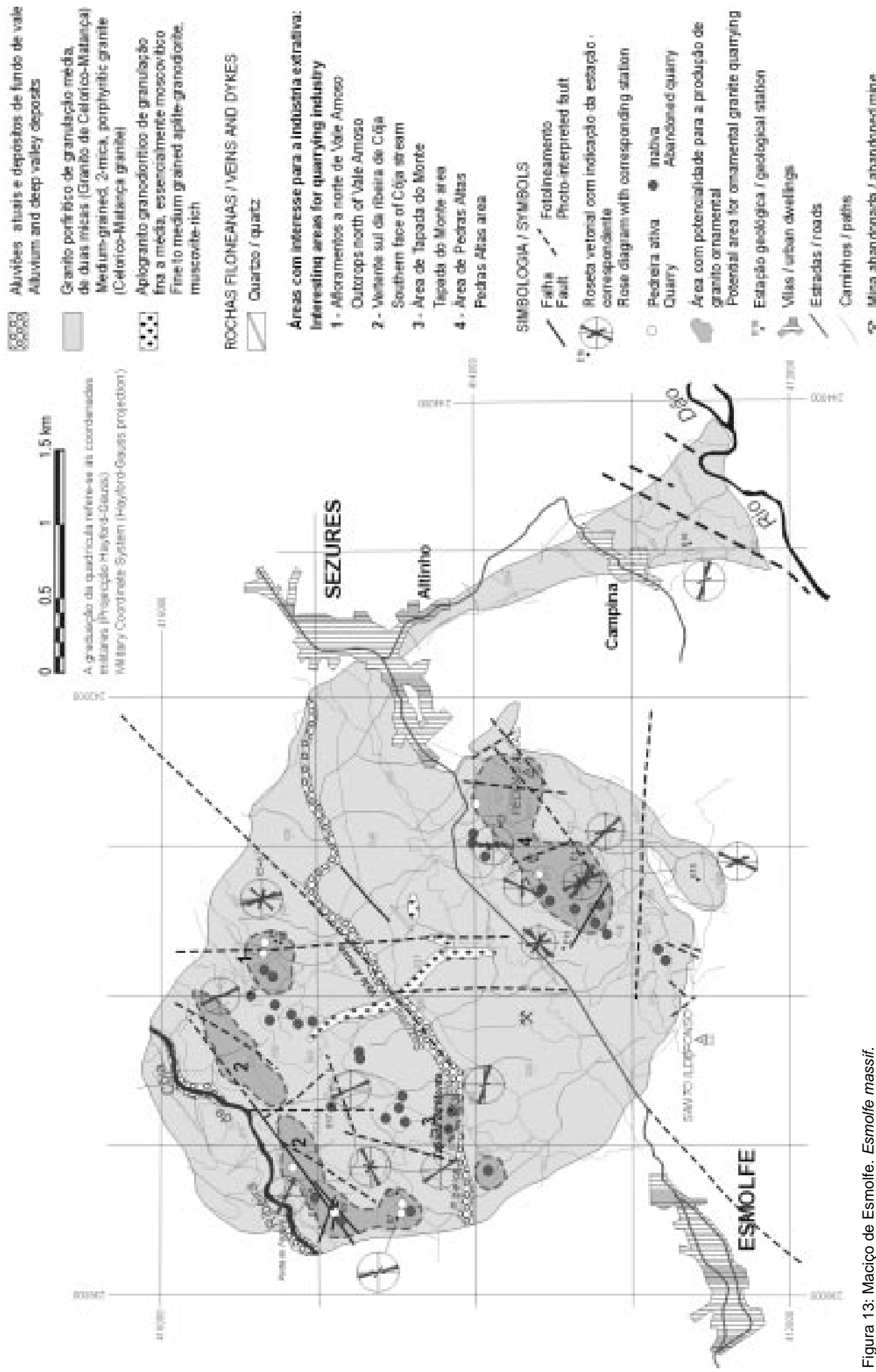



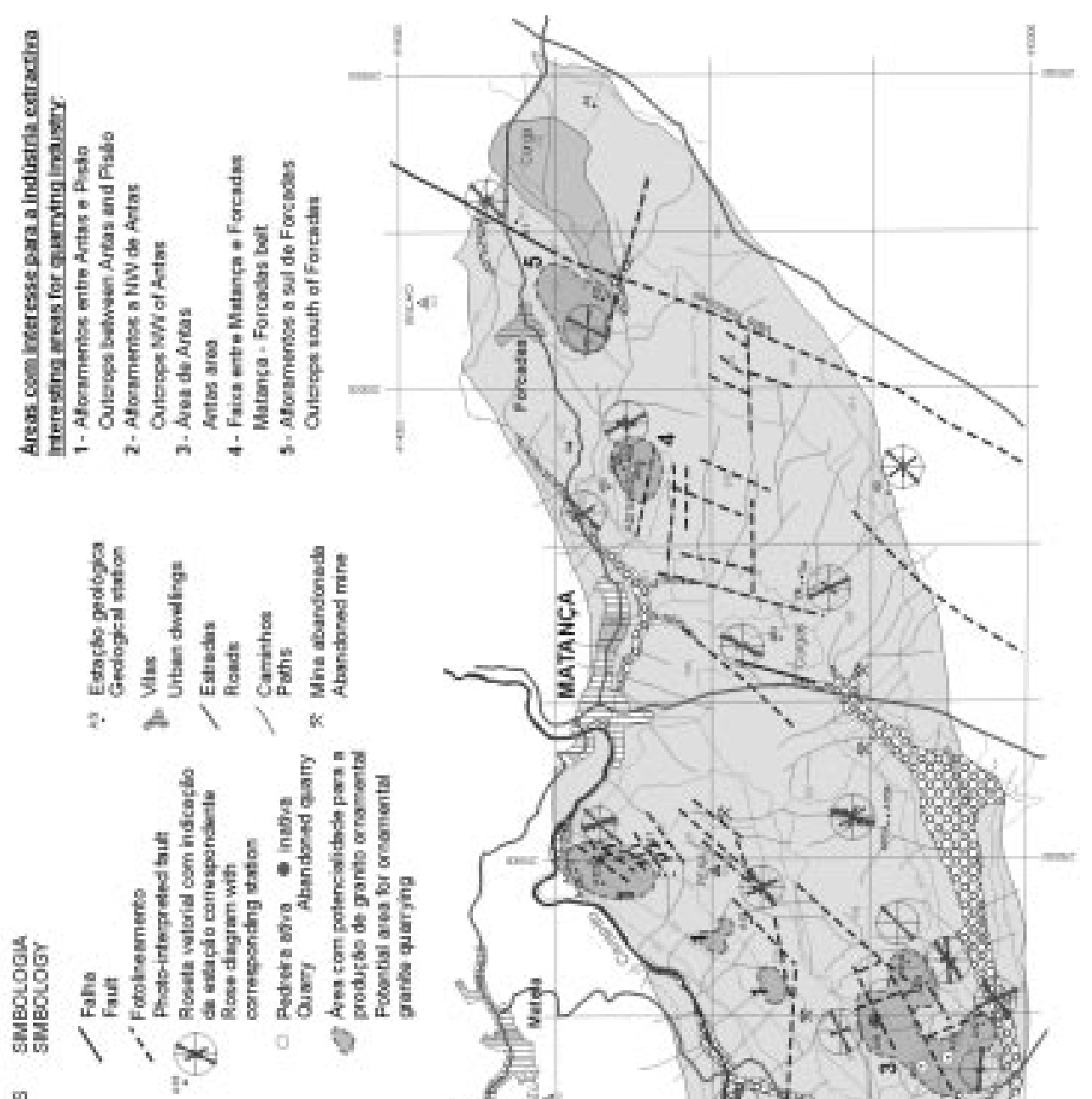

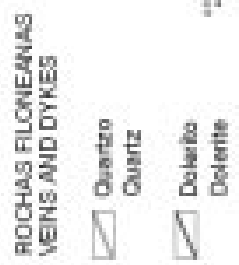
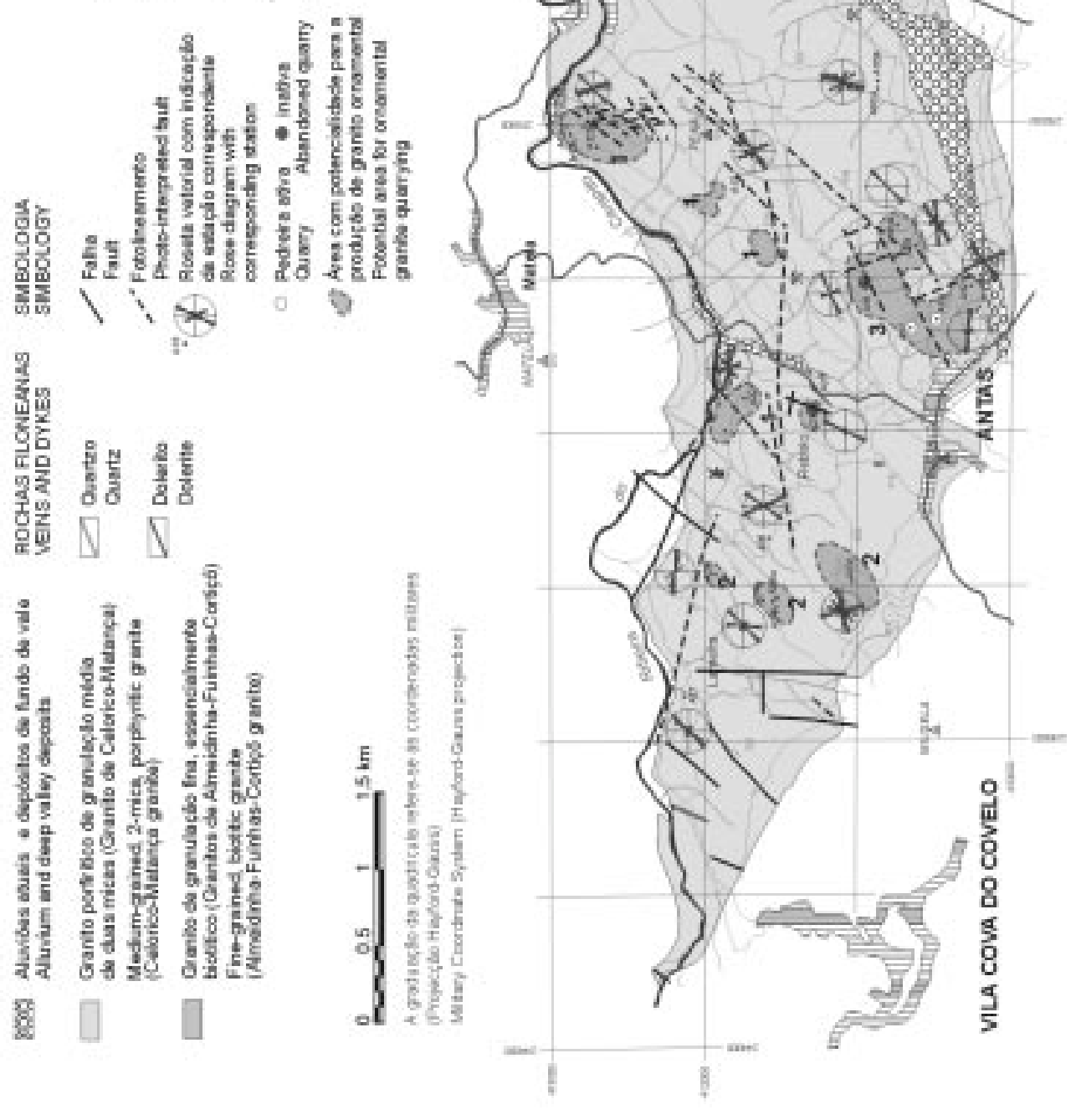

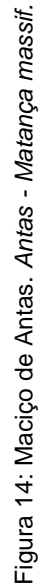


As juntas não sistemáticas, traduzidas numa maior dispersão das fracturas, têm maior influência em Esmolfe do que em Antas-Matança, o que contribui para uma dimensão mais irregular do bloco natural.

Embora o estudo do diaclasamento, efetuado em ambos os maciços, tenha sido a partir de dados de superfície, os espaçamentos verificados são indicadores da tendência em níveis mais profundos. Acrescenta-se o fato da tendência da fracturação decrescer geralmente com a profundidade, conforme se verifica nas pedreiras existentes.

Os espaçamentos são muito semelhantes em ambos os maciços, de moderados a amplos, sendo no conjunto ligeiramente maiores em Esmolfe; também a média de freqüência de fracturação observada neste último é menor que a média calculada em Antas-Matança.

As características da fracturação, aliadas à homogeneidade textural da rocha, características mineralógicas e físico-mecânicas favoráveis, além de outros fatores, como boas condições topográficas, facilidades de acessos e reservas elevadas, demonstram o elevado potencial ornamental destes maciços.

A atividade extrativa em Antas-Matança é, por enquanto, reduzida, limitando-se a três pedreiras ativas existentes na ocasião dos trabalhos de campo. Pelo contrário, a atividade em Esmolfe é intensa e bastante caótica. A proliferação exagerada de pedreiras que, raramente ultrapassam os níveis superficiais, causa um grande impacto visual. A ausência de orientação técnica na maioria das explorações faz com que os níveis mais promissores raramente sejam atingidos, razão pela qual as pedreiras são abandonadas no início.
Em Esmolfe, o material explorado possui elevado valor para a indústria extrativa, sobretudo nas áreas a SW de Pedras Altas e S de ponte do Ferreira.

Consideram-se como áreas de melhor aptidão no maciço de Antas-Matança, os afloramentos nas imediações de Pisão, nas regiões de Lameira (estação A24), de Antas e Abrocedo.

Este estudo permitiu um conhecimento razoável de ambos os maciços, particularmente do seu estado de fracturação e do potencial das áreas. Cabe salientar que os resultados aqui obtidos, tanto em superfície quanto em profundidade, são extrapoláveis apenas para as áreas contíguas aos locais estudados, e mesmo assim com reservas, pois a fracturação tem um componente de aleatoriedade elevada.

Finalmente, deve ser salientada a importância da realização deste tipo de trabalho, antes do início da atividade extrativa, pois desta forma é possível otimizar os custos e ter uma base de planejamento para atividades mais onerosas (utilização de georadar ou sondagens mecânicas com recuperação). Além disso, podem-se minimizar os efeitos ambientais e evitar as conseqüências desastrosas, como aquelas verificadas no maciço de Esmolfe.

\section{AGRADECIMENTOS}

Os autores agradecem a atenta revisão de uma versão inicial deste trabalho, pelo Dr. Jorge Silva Bettencourt e por um consultor anônimo que muito contribuiram para um trabalho mais conciso e mais legível.

\section{REFERÊNCIAS}

GARCÍA, E. O. Investigación de yacimientos. In: JIMENO, C. L. (Ed.). Manual de Rocas Ornamentales. Madrid: Entorno Gráfico S. L., 1995. p. 139-174.

GONÇALVES, L. S. M. et al. Folha n. 17-B (Fornos de Algodres) da Carta Geológica de Portugal, escala 1/50.000. Lisboa: Inst. Geol. e Mineiro, 1990.

INTERNATIONAL SOCIETY FOR ROCK MECHANICS COMMISSION ON STANDARDIZATION OF LABORATORY AND FIELD TESTS (ISRM-CSLF). Suggested methods for the quantitative description of discontinuities in rock masses. Int. J. Rock Mech. Sci. \& Geomech. Abstr., n. 15, p. 319-368, 1978.

LA POINTE, P. R.; HUDSON, J. A. Characterization and Interpretation of Rock Mass Joint Patterns. The Geological Society of America, Special Paper, n. 199, 37 p., 1985.
MOURA, A. C.; MARTINS, O. R. Catálogo de Rochas Ornamentais. Publ. do Laboratório do I.G.M., S. Mamede de Infesta. 1983.

MOURA, A. C. et al. Exploração de Maciços Graníticos. Contributo para uma nova atitude no aproveitamento racional e na valorização dos recursos. 1996.10 p. Relatório interno do IGM.

PINTO, M. S. et al. Síntese geocronológica doe granitóides do Maciço Hespérico. In: BEA, F. et al. (Eds.). Geologia de los granitoides y rocas asociadas del Macizo Hesperico. Libro de Homenaje a L. C. Garcia de Figuerola. Dep. Geologia, Univ. Salamanca, Madrid: Rueda, 1987. p. 69-86.

RAMOS, J. M. F. et al. Maciço granítico de Antas-Matança. Nota breve acerca da sua exploração para rocha ornamental. Relatório interno do IGM. 18/97, 1997. 9 p. 
LISBOA, J. V.; OLIVEIRA, D. P. S. Maciços graníticos de Esmolfe e Antas - Matança...

RIBEIRO, A. et al. Introduction à la Géologie Genérale du Portugal. Serv. Geol. Portugal, Lisboa,[c/autor: editora] 1979. $114 \mathrm{p}$.
SEGALL, P.; POLLARD, D. D. Joint formation in granitic rock of the Sierra Nevada. Geological Society of America Bulletin, n. 94, p. 563-575, 1983. 